\title{
NBSIR 74-564
}

\section{Development and Analysis of}

Techniques for Calibration of Kerr Cell Pulse-Voltage Measuring Systems VIII

Robert E. Hebner, Jr., Esther Christmas Cassidy

and Richard J. Sojka

Electricity Division

Institute for Basic Standards

National Bureau of Standards

Washington, D. C. 20234

August 21, 1974

Final Report on

Sandia Corporation Order No. FAO 28-0990

Sandia Requester and Technical Consultant: S. R. Booker, Org. 9532

Sandia Contracting Representative: John G. Boyes, Org. 4361

Prepared for

Sandia Corporation

Bldg. 894, Kirtland AFB

East Albuquerque, New Mexico 87115 
NBSIR 74-564

DEVELOPMENT AND ANALYSIS OF

TECHNIQUES FOR CALIBRATION OF KERR CELL

PULSE-VOLTAGE MEASURING SYSTEMS VIII

Robert E. Hebner, Jr., Esther Christmas Cassidy

and Richard J. Sojka

Electricity Division

Institute for Basic Standards

National Bureau of Standards

Washington, D. C. 20234

August 21, 1974

Final Report on

Sandia Corporation Order No. FAO 28-0990

Sandia Requester and Technical Consultant: S. R. Booker, Org. 9532

Sandia Contracting Representative: John G. Boyes, Org. 4361

Prepared for

Sandia Corporation

Bldg. 894, Kirtland AFB

East Albuquerque, New Mexico 87115

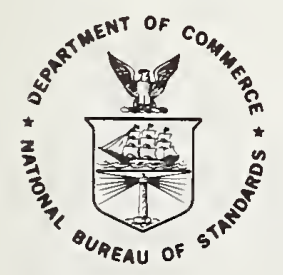

U. S. DEPARTMENT OF COMMERCE, Fredorick B. Dent, Secrotary

NATIONAL BUREAU OF STANDARDS, Richard W. Roberts. Director 


\section{TABLE OF CONTENTS}

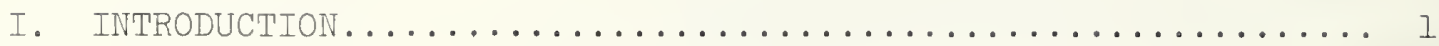

LI. CALIBRATION OF PULSE VOLTAGE MEAL REMENT SYSTEMS BASED

ON THE ELECTRO-OPTIC KERR EHFECI................ 5

III. KERR COEFFICIENT DETERMINATIONS....................... IO

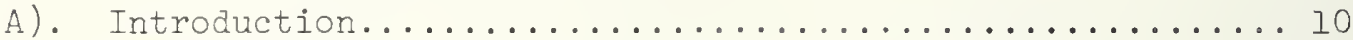

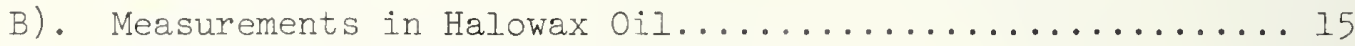

C). Temperature Dependence of the Kerr

Coefficient of Nitrobenzene...................... 22

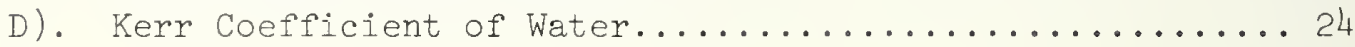

IV. ELECTRIC FIELD DISTRIBUTIONS AND SPACE CHARGE BEHAVIOR IN NITROBENZENE UNDER LOW FREQUENCY ALTERNATING VOLTAGE......... 28

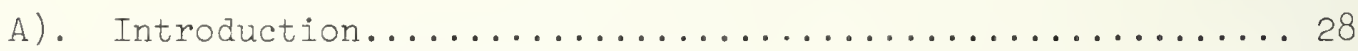

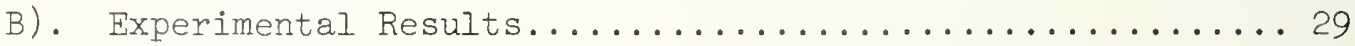

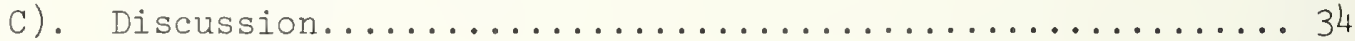

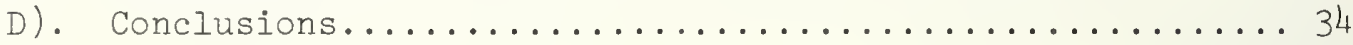

APPENDIX A: KERR EFFECT STUDIES OF AN INSULATING

LIQUID UNDER VARIED HIGH-VOLTAGE CONDITIONS. . . . . . . . . . 36

REFERENCES................................ 51 
This report documents recent progress in the refinement of techniques for the accurate calibration of pulsed voltage measurement systems based on the electro-optic Kerr effect. Previous results, and this year's work, can be categorized into four main areas. The first area, and the primary reason for this project, is the calibration of pulsed-voltage measurement systems. Historically the Kerf system has been used as an adjunct to a conventional resistive divider to measure the high voltage pulse which was applied to the system under test. The rationale for this was that the sources of error in Kerr measurements are different from those in divider measurements. Thus if the values obtained by the two methods agreed to within their combined uncertainties, it is unlikely that there is significant error in either. Such a dual system is, in this respect, self-checking thereby minimizing the effects of operator error. Experience with Kerr systems used in this manner has demonstrated the long term stability of the calibration. More recent work has focused on the use of a Kerr system for inter-laboratory transfer of calibration.

To gain an appreciation of the utility of a Kerr system both as an adjunct to a conventional system and as a transportable system for in situ calibration of conventional systems, it is helpful first to examine the difficulties that have been identified in conventional measurements. The yarious sources of divider errors are included in the following list $^{1,2}$ :

1. Residual inductance in any resistance or capacitance element.

2. Stray capacitance - (A) from any section of the divider to ground or a grounded object, (B) from any section of the divider to high voltage parts of the supply and test circuit, and (C) between sections of the divider.

3. Impedance drop in the lead from the point at which the high voltage is to be measured to the high voltage end of the divider.

4. Impedance drop in the ground return lead from the divider due to either extraneous ground currents flowing in this lead or to the divider current.

5. Oscillations set up in the divider circuit caused by capacitance from the divider high voltage terminal to ground and lead inductance.

Although the first source of error is intrinsic to the divider, the other four error sources depend to some extent upon the arrangement of the experimental apparatus. The calibration of a divider in one laboratory for use in another is of value only for the identification of intrinsic faults of the divider but does little to verify accurate measurement. A Kerr system, being much less susceptible to stray capacitance and ground current errors, is an attractive device for 
in situ calibrations of resistive and cépacitive dividers. In Section II of this report, the calibration of Kerr systems is discussed with emphasis on the transportability and long-term stability of the calibration.

There is one important facet of calibration of Kerr systems that requires additional work. Present practice is to calibrate cells against a carefully constructed resistive divider which has an estimated uncertainty of $\pm 1 \% .^{1}$ Because the relative permittivity of nitrobenzene is approximately independent of frequency over the frequency range from $0-10^{7} \mathrm{~Hz}$, it has been postulated that the Kerr response should also be independent of the frequency of the applied voltage over this same range. If this be the case, it would then be possible to calibrate a cell at a single frequency at full operating voltage. The significance of a single frequency calibration of a Kerr system can be seen from the following brief review of current practice for the calibration of pulse measurement systems not using the electro-optic Kerr effect.

In addition to the Kerr systems described in this report, there are two other techniques for measuring pulsed high voltage. These are the use of a carefully constructed divider to provide a lower voltage pulse for measurement using an oscilloscope or other appropriate measuring device and the use of the breakdown of a sphere gap. Traceability to basic standards is maintained through the divideroscilloscope system of measurement, while the sphere gap is used to insure consistency among various laboratories throughout the world. The present measurement techniques permit best estimates of the measurement uncertainty of $\pm 1 \%$ for voltage pulses having a peak value of less than one million volts and a risetime longer than about $1 \mu s$. Typical uncertainties for this type of voltage pulse are $\pm 3 \%$. These uncertainty estimates rapidly become larger for higher voltage levels and/or shorter risetimes. The accepted procedure for calibration of resistive dividers is to measure both the resistance ratio and the response of the divider to a step vol.tage at low voltage in a system designed so that there is no significant voltage dependence of any component.

Against this background the significance of a single frequency calibration can be evaluated. If a Kerr system can be calibrated at a single frequency or a number of discrete frequencies and if it can be verified that this calibration is frequency independent over a sufficiently wide range, it will then be possible to measure pulsed high voltage using a method which is independent of previous high voltage pulse measurements. In addition to being independent, this approach shows promise of being more accurate than previous measurement techniques.

The basis for the expectation of more acurate measurements is that, at a number of discrete frequencies, it may be possible to measure more accurately the voltage applied to the cell. At a single, low frequency (below about $5 \mathrm{kHz}$ ), dividers are routinely constructed with division ratios having uncertainties of order $\pm 0.1 \%$ and can be constructed with uncertainties as 1 ow as $0.001 \%$. In addition the rms value of the 
applied voltage can be determined with an uncertainty of order $0.01 \%$. Assuming that it is possible to devise a sufficiently stable voltage source and detection system that will provide a measurement of the waveshape of a single half cycle of the applied voltage, it may be possible to compare the Kerr system response to a device possessing a measurement uncertainty of only $\pm 0.1 \%$.

Previous work has addressed itself to calibration under direct voltage and low frequency (less than $150 \mathrm{~Hz}$ ) alternating voltage of nitrobenzene-filled Kerr cells. Calibrations under direct voltage have been performed which agree with calibrations using a divideroscilloscope voltage measurement system to within the uncertainty of the conventional system, i.e., to within $\pm 1 \%$. Electric field distortion due to space charge in the liquid discourages more precise comparison. This report contains a discussion of the frequency dependence of the space charge dynamics in the liquid and of measurements using a Halowax oil-filled Kerr cell under direct, $60 \mathrm{~Hz}$ and pulsed high voltage. It was decided to use Halowax oil because it should not be as sensitive to the effects of impurities as nitrobenzene. Calibrations under these three different types of waveform disagreed by about $\pm 1 \%$ of the average.

The second area into which the Kerr effect work can be categorized is the measurement of the spatial and temporal behavior of the electric field. The work is a spin-off from and serves as the basis for the attempt at a single frequency calibration. Previous reports ${ }^{7} 8$ have documented the measurement of the electric field distribution which is attributable to the geometry of the cell. Appendix A of this report contains a reprint of a journal article which summarizes the work at NBS directed toward the measurement of electric field distributions under direct and low frequency alternating voltage.

The third broad class of Kerr effect work deals with the development of instrumentation based on the use of the electro-optic Kerr effect for pulsed voltage measurements. In last year's report, NBS IR 73-403, a measurement system based on the concept of counting the output pulses from the Kerr system was presented. Tests of the system were described which indicated its attainable accuracy.

In this year's report the test of a system developed by Sandia Laboratories is discussed. The precision, accuracy and operating characteristics are presented. In addition a novel system for more accurate measurement of the phase shift when direct voltage is applied to the cell is presented. Having determined its operating characteristics, refinements are being made and an improved system will be developed during the coming fiscal year.

The final class of Kerr effect work is the determination of the Kerr coefficients of various materials. There are three reasons for the significance of this work. One is that accurate values of the Kerr coefficient permit accurate voltage measurements in situations in which 
calibrations of the Kerr system is impractical; the cell constant is computed from the geometry of the cell and the Kerr coefficient. Second, accurate values of the Kerr coefficient are necessary so that Kerr systems with predictable response can be designed and constructed. The final reason for the measurement of the Kerr coefficient of various liquids is to provide a check on the accuracy of the measurement system employed. The Kerr coefficient is given approximately by the expression ${ }^{6}$

$$
\varphi=2 \pi B l^{\prime} V^{2} / d^{2},
$$

where $\varphi$ is the phase shift between orthogonally polarized components of the light beam, B is the Kerr coefficient, $V$ is the applied voltage, and a parallel plate geometry is assumed with the plates having an effective length $l^{\prime}$ and spaced a distance d apart. The determination of $B$ requires measurement of the optical phase shift, geometry and voltage. Comparison of measurements of the Kerr coefficient with previous results provides a measure of accuracy of the total measurement system. In addition, calibration of a Kerr cell consists of determining the magnitude of the constant of proportionality between square root of the phase shift and the applied voltage. As can be seen from inspection of Eq. 1, this constant of proportionality is determined by the Kerr coefficient of the birefringent medium used and by the geometry of the cell. The change in the Kerr coefficient per change in temperature is about three orders of magnitude larger than the change in cell geometry with a change in temperature. It has therefore been determined that the temperature dependence of the cell calibration is determined by the temperature dependence of the Kerr coefficient to within the measurement accuracy. The metrological significance is that a given cell needs to be calibrated at a single temperature and corrections for temperature variations can be made through a knowledge of the properties of the birefringent fluid.

A description of the calibration of Kerr cells provided by Sandia Corporation is presented in Section II. Section III consists of a discussion of the Kerr coefficients of water, Halowax oil and nitrobenzene. Section IV is a discussion of the dependence of the space charge dynamics in nitrobenzene on the frequency of the applied voltage. This discussion serves as an introduction to the attempt at a single frequency calibration which will be performed during FY 75. Following established practice, an article entitled "Kerr-Effect Studies of an Insulating Liquid Under Varied High Voltage Conditions" which was published in IEEE Transactions on Electrical Insulation and which was partially supported by this contract is included as an appendix to this report. 
II. Calibration of Pulse Voltage Measurement Systems Based on the Electro-optic Kerr Effect.

During October 1973 Sandia Corporation submitted to the National Bureau of Standards for calibration a system for the measurement of pulsed high voltage. This system, based on the electro-optic Kerr effect, was unique for a variety of reasons. First, it employed a double-pass optical system. That is, the polarized light beam would pass through the Kerr cell, impinge upon a mirror and be reflected back through the Kerr cell, effectively doubling the length of the cell. This permits good sensitivity in a cell that is physically small and, although cell capacitance does not usually present a problem, it too is reduced as the plate length is reduced. The second novel characteristic was that the entire systen was packaged in a single enclosure. To use the system one needed merely to supply power to the system, attach the voltage to be measured to one set of terminals and an oscilloscope to another terminal to detect the system's output. The third interesting characteristic of this system was that it was designed to accommodate three different Kerr cells with nominal plate spacings of $0.2,0.5$, and $1.0 \mathrm{~cm}$. This permitted measurement of pulses with peak voltages ranging from a few thousand volts to over one hundred thousand volts.

Previous work ${ }^{5}$ has amply documented that, in Kerr cells having the electrodes immersed in the birefringent fluid, fringing edge fields may produce significant path dependent variations in the system's transmittance at a given voltage level. Throughout the development of this measurement technique several alternative solutions to this problem have been considered including: 1) correction by design ; 2) confinement of the light ${ }_{8}$ ath; 3) multiple calibration for all likely measurement paths ${ }^{8} ;$ ) development of reliable procedures for correcting path dependent errors . In the system under test, the effect of fringing fields was minimized using the second approach, confinement of the light path. Definition of the position of the light path with respect to case in which the system was housed was accomplished using a series of aperatures between the light source and the photodetector. The Kerr cells are then fastened to the case with screws to insure both that they do not move during the course of a measurement and that when a cell is removed it can be replaced in exactly the same position.

The essential features of the calibration system are shown in Fig. 1. The trigger generator and the two delay units control the timing of the high voltage pulse generator and the oscilloscopes used to measure and record the response of the various measurement systems to the applied voltage pulses. The pulse amplifier supplies a high voltage pulse of sufficient magnitude to trigger the Marx generator. To perform the calibration, three measurement systems are connected in parallel. These are a $500 \Omega$ resistive divider, a calibrated (by reference to the divider) Kerr cell and the Kerr cell under test. The peak of the applied voltage pulse is determined by using a slideback ${ }^{7}$ technique to display the low side voltage of the divider. During the same voltage pulse, the responses of both the calibrated Kerr cell and the Kerr cell under test are recorded. 


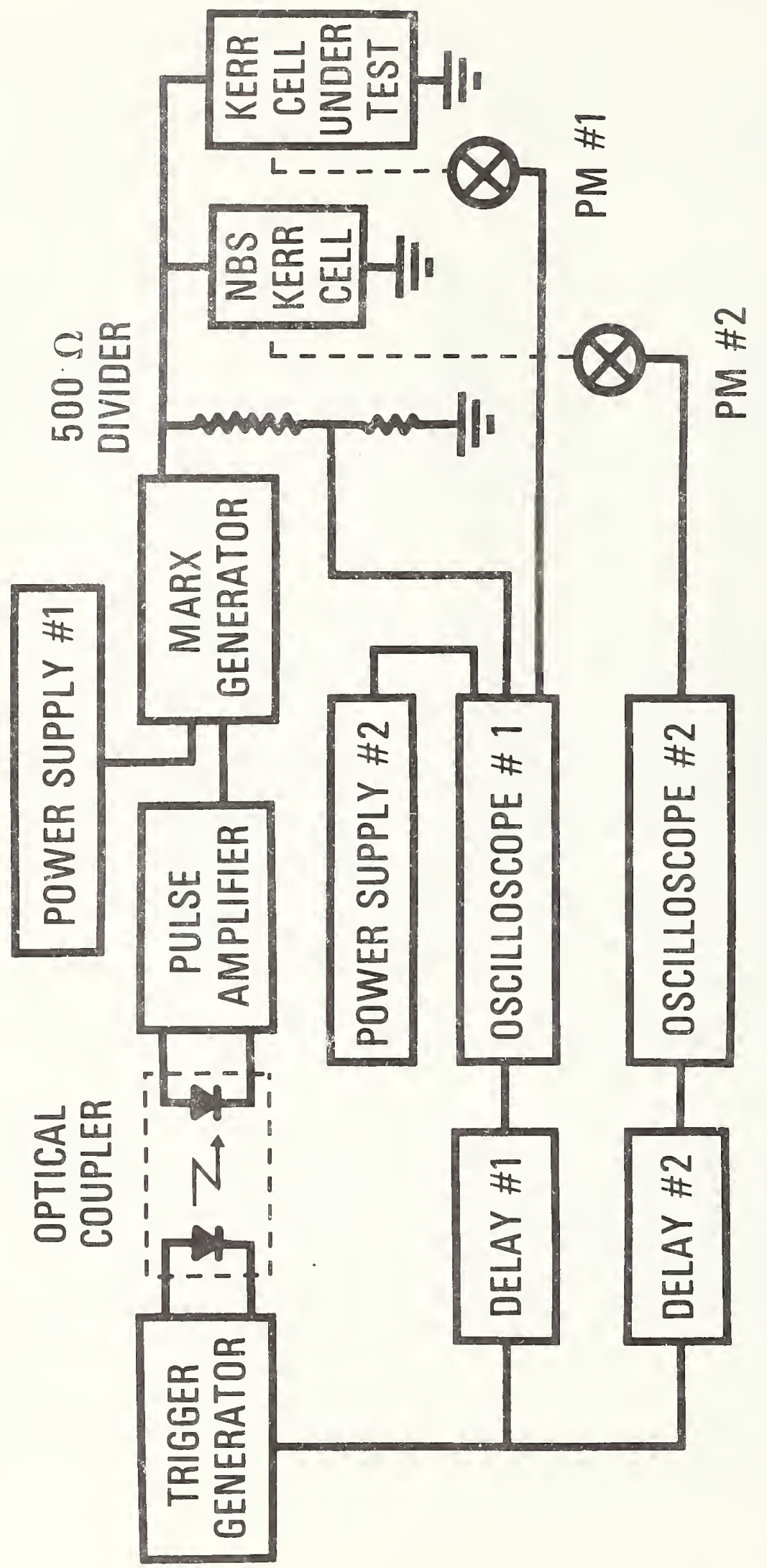

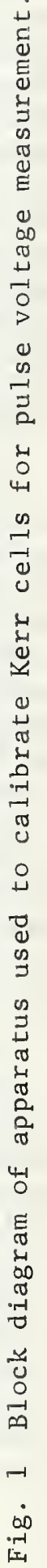


The optical coupling between the trigger generator and the pulse amplifier is used to reduce the ground current error in the divider measurement by eliminating the ground loop that would occur through the interconnection of the trigger generator, pulse amplifier, Marx generator, resistive divider, oscllloscope and delay generator. In more than six months of operation the optical coupling system has proven to be a cheap, effective and reliable method of transmitting information. The optical coupler used is capable of transmitting pulses of duration greater than approximately 1 us and a peak input voltage of $35 \mathrm{~V}$.

The data obtained from the cell caltbration is summarized in Table 1. It should be noted that for these data the total uncertainty is estimated to be $\pm 2 \%$. This estimate is larger than the $\pm 1 \%$ which is typically attributed to this type of calibration because the supplied cells did not incorporate any method for measurement or control of temperature.

The calibration of cell A required the application of voltage pulses that were at the limit of the lowest voltage pulses that are conveniently available in the Electricity Division of the National Bureau of Standards. Measurements were made, therefore, only at nominal peak values of $13,14,15 \mathrm{kV}$. All pulses used in this callbration had a risetime of approximately $1 \mu \mathrm{s}$ and a duration of about $10 \mu \mathrm{s}$.

Table 1. Results from the calibration of Sandia Corporation Kerr cells. This compilation of data is intended to document the variation of the observations as the total uncertainty, both systematic and random is $\pm 2 \%$.

\begin{tabular}{|c|c|c|c|c|}
\hline Ce 11 & $\begin{array}{l}\text { Plate } \\
\text { Spacing } \\
\text { (cm) }\end{array}$ & $\begin{array}{c}\text { Nominal Value } \\
\text { of Applied Voltage } \\
(\mathrm{kV})\end{array}$ & $\begin{array}{c}\mathrm{v}_{\mathrm{m}} \\
\text { (volts) }\end{array}$ & $\begin{array}{c}\text { Number of } \\
\text { Observations }\end{array}$ \\
\hline A & 0.2 & $\begin{array}{c}13 \\
13-15\end{array}$ & $\begin{array}{l}1694 \\
1686\end{array}$ & $\begin{array}{r}5 \\
23\end{array}$ \\
\hline B & 0.5 & $\begin{array}{l}15 \\
30 \\
45 \\
60\end{array}$ & $\begin{array}{l}5931 \\
5948 \\
5945 \\
5949\end{array}$ & $\begin{array}{l}5 \\
5 \\
5 \\
5\end{array}$ \\
\hline C & 1.0 & $\begin{array}{r}45 \\
60 \\
75 \\
78 \\
101\end{array}$ & $\begin{array}{l}12564 \\
12585 \\
12578 \\
12608 \\
12578\end{array}$ & $\begin{array}{r}4 \\
5 \\
5 \\
7 \\
13\end{array}$ \\
\hline
\end{tabular}


During the calibration of cell C, it was necessary to use a second pulse generator to obtain data with an applied voltage of $100 \mathrm{kV}$. For the measurements at 78 and $101 \mathrm{kV}$ this second pulse generator was used. In that case it was not possible to measure the waveform with the $500 \Omega$ resistive divider. In those two sets of measurements the applied voltage was measured only with the calibrated Kerr cell which served as a portion of the measurement systems in the other measurements.

Fig. 2 graphically demonstrates the precision of the measurements. This figure shows a normalized distribution of the percent deviation from the average of each determination of the cell constant of cell A for the set of 23 measurements listed in Table 1. It can be seen that no measurement differed from the average by more than about $0,2 \%$. The total width of the graph is $\pm 2 \%$, the total uncertainty estimated for this measurement.

Because the cell constant changes approximately $0.5 \% / \mathrm{C}$ for temperatures near room temperature, it is obvious from Fig. 2 that the temperature remained approximately constant during this set of measurements.

In order to document the utility of the Kerr system to transfer accurate pulsed voltage measurements between laboratories, the results of calibrations of cells submitted by Sandia Corporation and by another user are listed in Table 2 .

Table 2. Comparison of Kerr cell calibrations by NBS and by the cell owners in their own laboratories.

$\operatorname{Ce} 11$

Ce11 Constant Determination by

Difference NBS

1690

(voits)

A

5960

1710

1.2

B

12600

5990

0.7

C

23640

12600

0.0

D

21450

23640

0.0

E

21500 (1973)

21440

0.3 


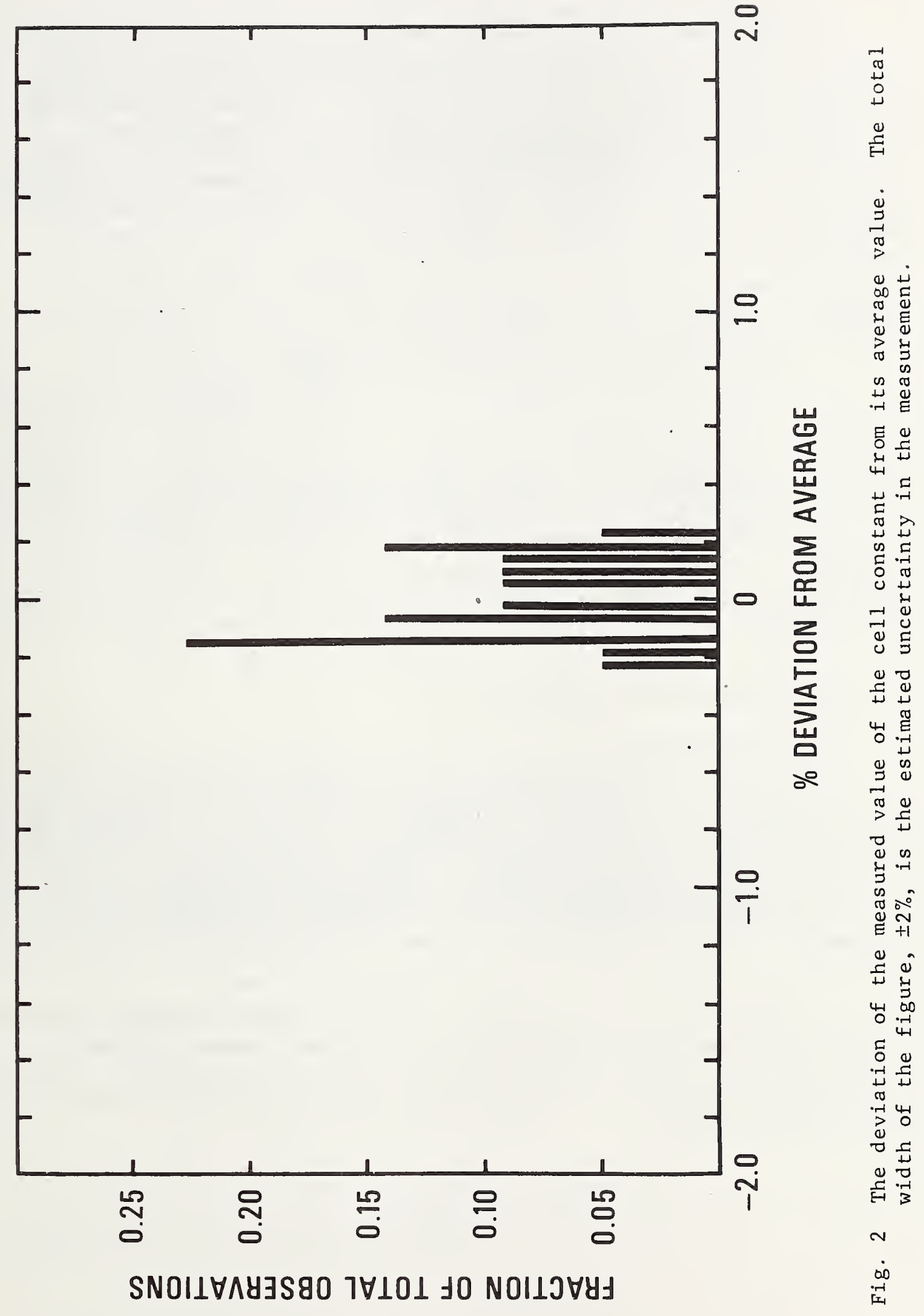


It should be noted that this compilation is not a result of a controlled test, but merely a tabulation of the cells calibrated by NBS in which the owner volunteered the value that he obtained during his tests of his cells. The results may not, therefore, reflect the best efforts of the laboratories involved. Even granting this qualification, there are interesting observations that can be drawn from this limited data base. First, the largest percentage difference observed was $1.2 \%$. The only other method for comparing pulsed voltage measurement accuracy between laboratories is based on the breakdown voltage of a sphere gap. The tabulated values for sphere gap breakdown voltages have an estimated uncertainty of $\pm 3 \% .^{9}$ The limited data available indicates that the Kerr system is at least no worse than the traditional technique and holds promise of possibly being better.

The second point of emphasis concerning the results presented in Table 2 concerns the calibration of cell E. This cell was calibrated by NBS in 1970 and shipped to the owner. For three years it was used by the owner and NBS had no control over nor any information concerning its use and handling. After that three year period it was returned for recalibration and the value of the cell constant had changed by about $0.2 \%$. As indicated in Fig. 2, this change is comparable to the precision of the measurement. Long term stability of this sort has been observed in cells in use at NBS, but this is the first information NBS has obtained of similar long-term stability of cells used by others.

\section{Kerr Coefficient Determinations}

\section{A). Introduction}

During this contract period, the electromoptic properties of three substances, nitrobenzene, Halowax oil, and water, were investigated. In nitrobenzene the temperature dependence of the Kerr coefficient was remeasured, over a wider temperature range than previously, to insure that there was no anomalous behavior. The Kerr coefficient of Halowax oil was measured under direct, $60 \mathrm{~Hz}$ alternating, and pulsed high voltage. The Kerr coefficient of water was measured under pulsed high voltage.

In order to provide insight into the role these measurements play in the development of accurate pulse voltage measurement systems, it is necessary to review the nature of Kerr effect measurements. In the calculation of volfage from Kerr effect data, the following relationship is frequently used ${ }^{5}$,

$$
I / I_{m}=\sin ^{2}\left[\pi\left(V / V_{m}\right)^{2} / 2\right]
$$


In this relationship I is the transmittance of the optical system and $V_{\mathrm{m}}$ is the lowest voltage which causes a maximum in the system's transmittance, $I_{m}$. If $V_{m}$ is known and $I / I_{m}$ is measured, $E q .2$ can be used to determine the applied voltage from the Kerr-effect measurement. Similarly, the calibration of a Kerr system consists of the application of a known voltage to the cell, measurement of $I / I_{m}$ and calculation of $\mathrm{V}_{\mathrm{m}}$ from $\mathrm{Eq} \cdot 2$. In terms of more fundamental quantities,

$$
\mathrm{V}_{\mathrm{m}}=\mathrm{d}\left(2 \mathrm{~B} \ell^{\prime}\right)^{-1 / 2}
$$

where $B$ is the Kerr coefficient of the birefringegt fluid and $d$ the spacing and $l^{\prime}$ the effective length of the plates, as parallel plate geometry is assumed.

To obtain a semi-quantitative insight into the stability of the calibration of the Kerr coefficient with respect to wavelength, temperature, frequency of the applied voltage, etc., it is helpful to examine the classical expression of the Kerr constant of a polar fluid ${ }^{9}$,

$$
B=\pi \rho\left(n^{2}+2\right)^{2}(\varepsilon+2)^{2}\left(\theta_{1}+\theta_{2}\right) / 27 n \lambda
$$

In this equation, $\mathrm{n}$ is the index of refraction of the medium at the wavelength of the incident light $\lambda, \varepsilon$ is the dielectric constant of the medium, and $\rho$ is the number density of the molecules. $\theta_{1}$ and $\theta_{2}$ represent expressions involving the temperature of the fluid, the static and optical polarizabilities and the dipole moment of the molecule. This equation is approximate and has been shown to be inadequate for quantitative analysis, but does indicate the sources of variation of the magnitude of the Kerr coefficient.

The first point that is to be made explicit is the temperature dependence. From previous work ${ }^{9,10}$,

$$
\theta_{1}+\theta_{2}=\alpha_{0}+\alpha_{1} / T+\alpha_{2} / T^{2}
$$

so, suppressing all other dependencies, 


$$
B=A_{0}+A_{1} / T+A_{2} / T^{2}
$$

In the above expressions, the $\alpha^{\prime} s$ and the $A^{\prime} s$ are constants and $T$ represents the temperature of the material. In the previous year's contract report the temperature dependence of $B$ was presented. In this report a repetition of that work covering a wider temperature range will be documented.

Returning to Eq. 3, it can be seen that in the absence of dispersion, i.e., if the index of refraction is independent of wavelength, the quantity $B \lambda$ should be a constant. Measurements in our laboratory 7 indicate that at $296.1 \mathrm{~K}, \mathrm{~B} \lambda=2.171 \times 10^{-18}(\mathrm{~m} / \mathrm{V})^{2}$, but that over the range of wavelength from 632.8 to $476.5 \mathrm{~nm}$, the variation from this average was of order $\pm 3 \%$.

The final observation to be made from Eq. 3 is that the only factor which depends on frequency of the applied voltage, for frequencies below $10^{8} \mathrm{~Hz}$, is the relative permittivity. The relative permittivity of nitrobenzene and of Halowax oil are presented as functions of frequency ${ }^{11}$ in Fig. 3. The primary characteristic of these data is that both plots exhibit an approximately flat frequency dependence for frequencies below about $10^{8} \mathrm{~Hz}$. (Note that similar data by clark ${ }^{12}$ indicate that there is no change in slope between $10^{6}$ and $10^{8} \mathrm{~Hz}$ ). A conclusion that can be drawn from these observations is that the Kerr coefficient should be independent of frequency over a range of six to eight decades.

Measurements of the cell constant of a Halowax-filied cell were performed under direct, $60 \mathrm{~Hz}$ alternating, and pulsed high voltage. The motivation for these measurements was the hypothesis that Halowax oil, being a poorer solvent than nitrobenzene, would also be less susceptible to space charge distortion. The relationship between its physical properties and the applicability of fluid for use in a Kerr system has beem summarized by Felici ${ }^{13}$ and relevant portions are presented in Table 3. 


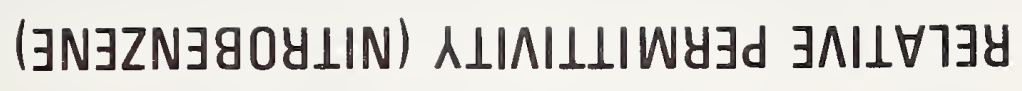

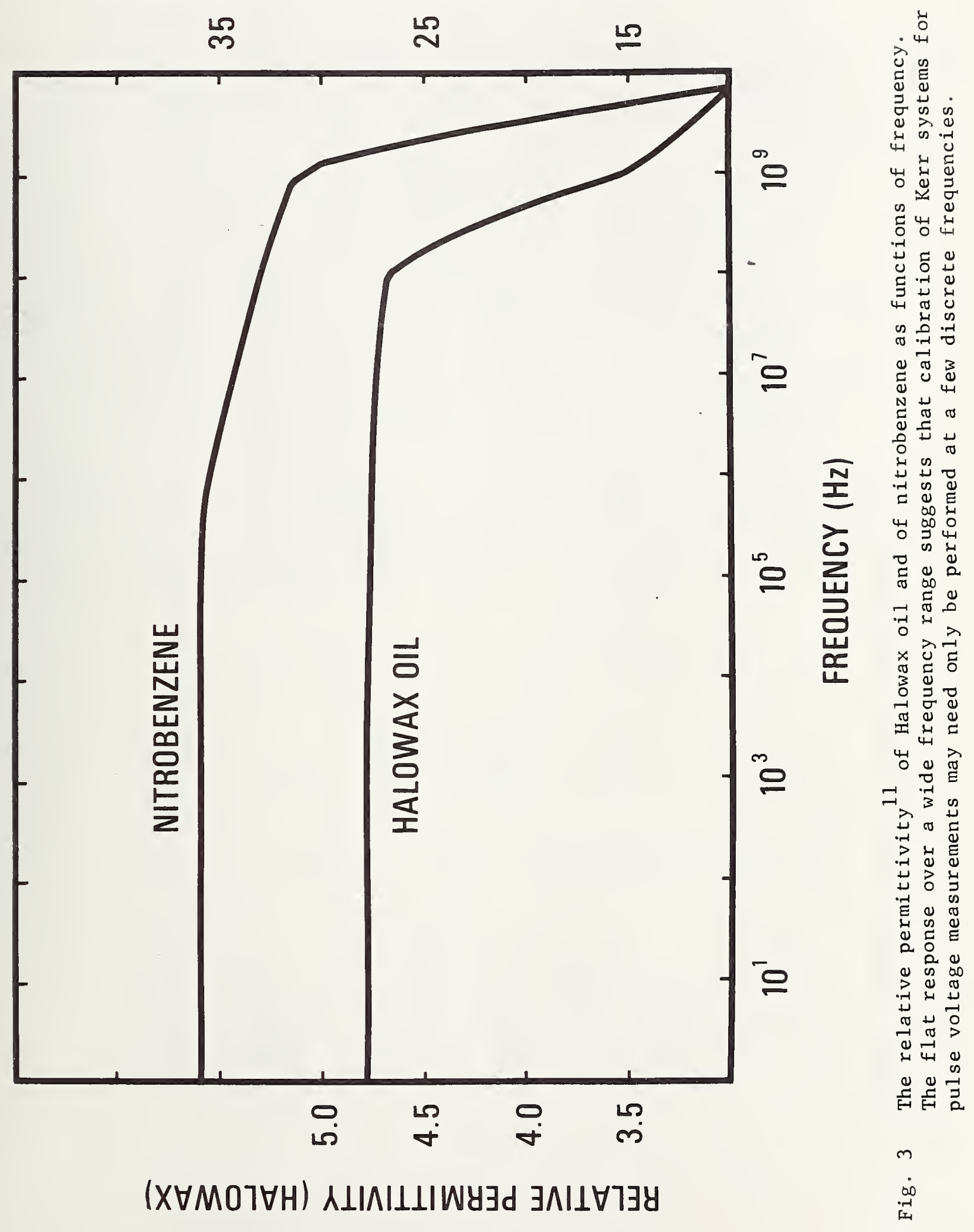




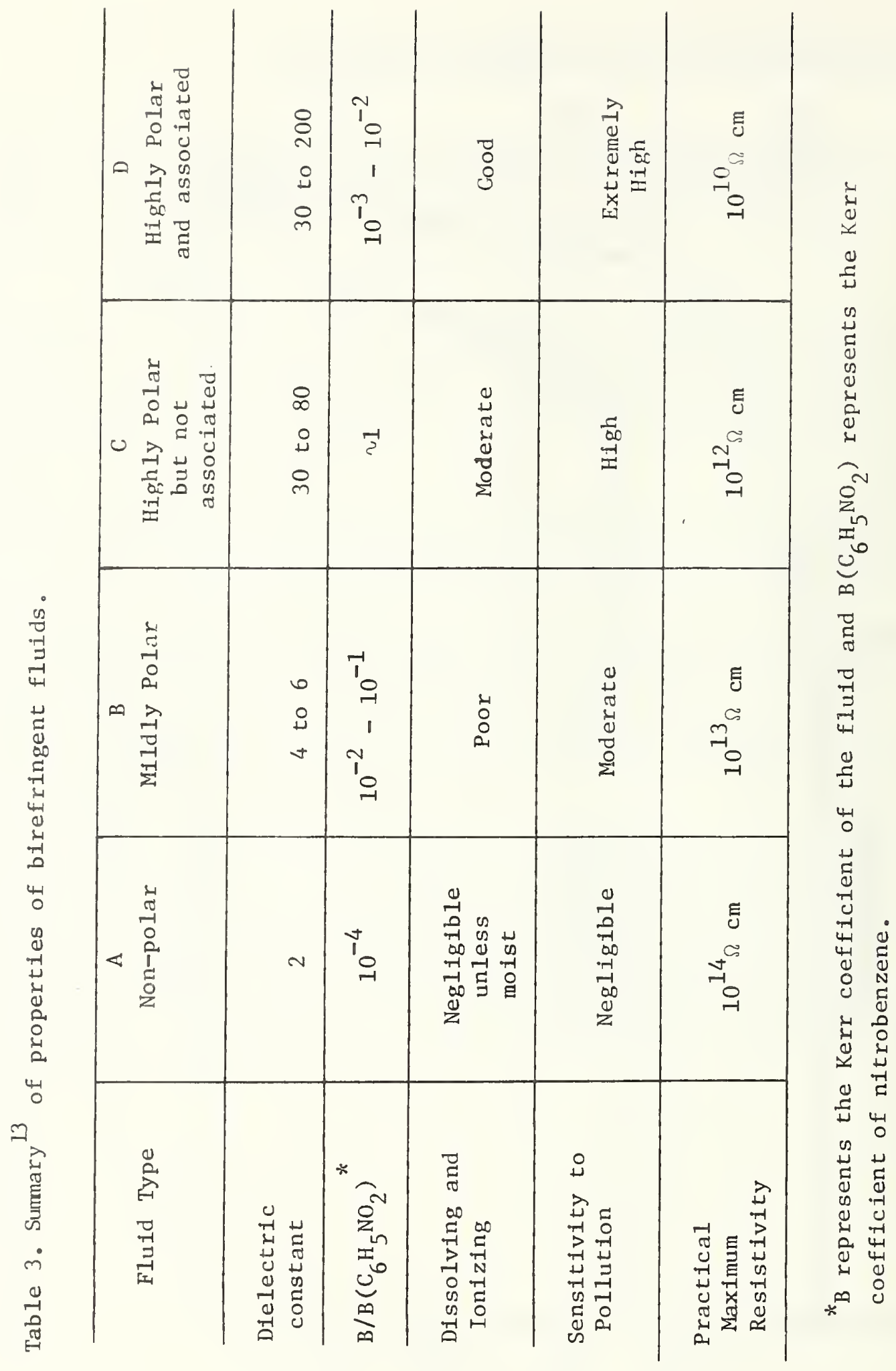


During the course of this work, investigations were made using a type B fluid, Halowax oil, a type C fluid, nitrobenzene, and a type D fluid, water.

B). Measurements in Halowax Oil.

A schematic diagram of the apparatus used to determine the cell constant under direct voltage of a Halowax oil-filled cell is presented in Fig. 4. Because data were accumulated over the range in which the phase shift between the orthogonally polarized components of the light beam was less than $\pi / 2$, it was desirable to modulate the light beam so that frequency sensitive detection could be used. The light beam was intensity modulated upon passage through a rotating chopper wheel. The chopped beam then impinged upon a beam splitter where one component of the light beam passed through a conventional polarizer--Kerr cell--analyzer system to one photodetector while the other portion of the light beam was reflected from the beam splitter into a second photodetector. The output from this photodetector was then amplified and shaped so that it would provide a stable reference frequency for the lock-in amplifier. In order to accumulate the data, the amplified and rectified signal from the lock-in amplifier was connected to the y-axis, while the analog output of a digital voltmeter was connected to the $x$-axis of an $x-y$ recorder. A typical data run was retraced and is shown in Fig. 5. Determination of the cell constant consisted of measuring the applied voltage and the corresponding transmittance and calculating $V_{m}$ from Eq. 2. Typical numerical values of the cell constant obtained from observations like the one presented in Fig. 5 are listed in Table 4. 


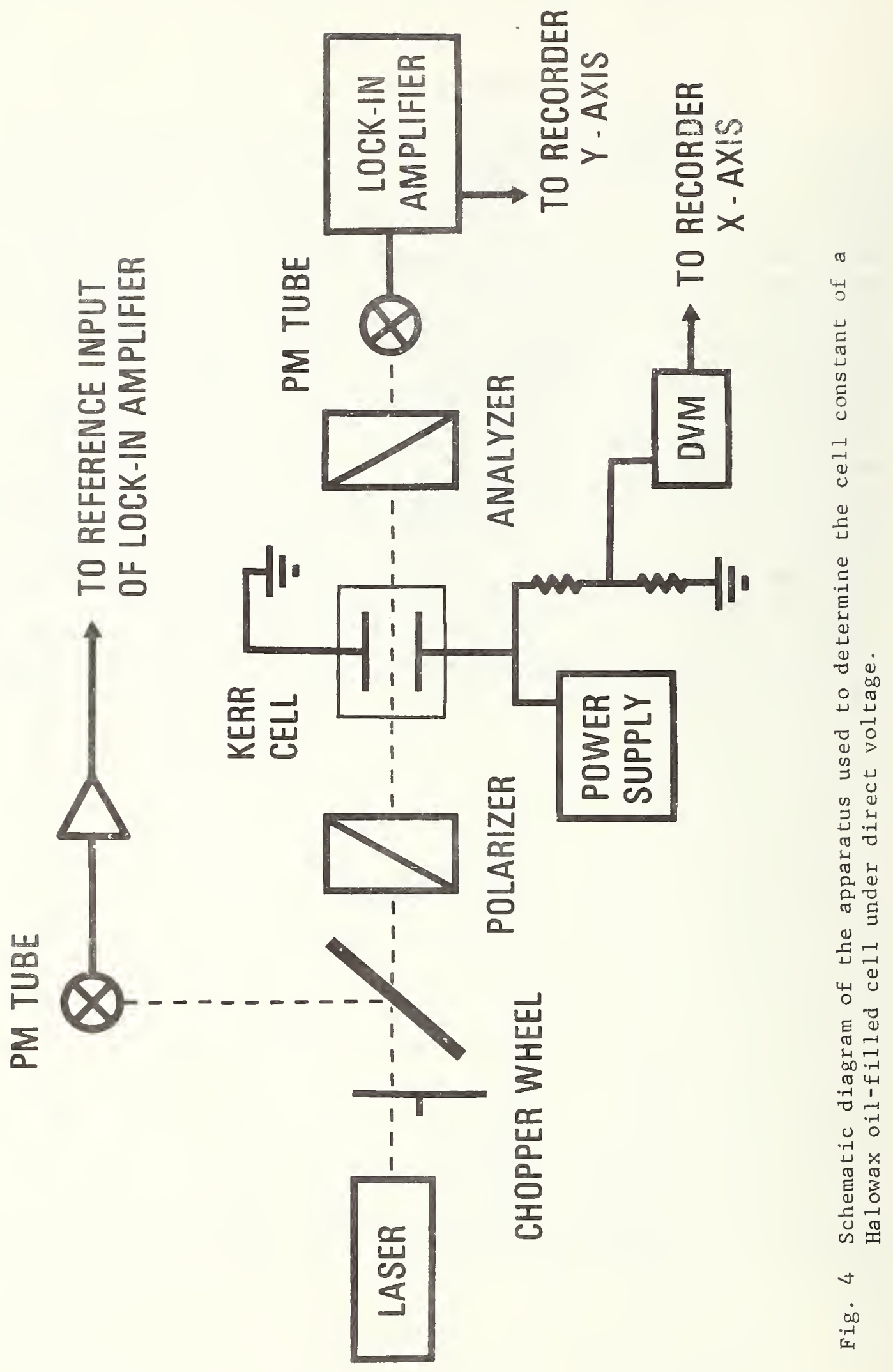




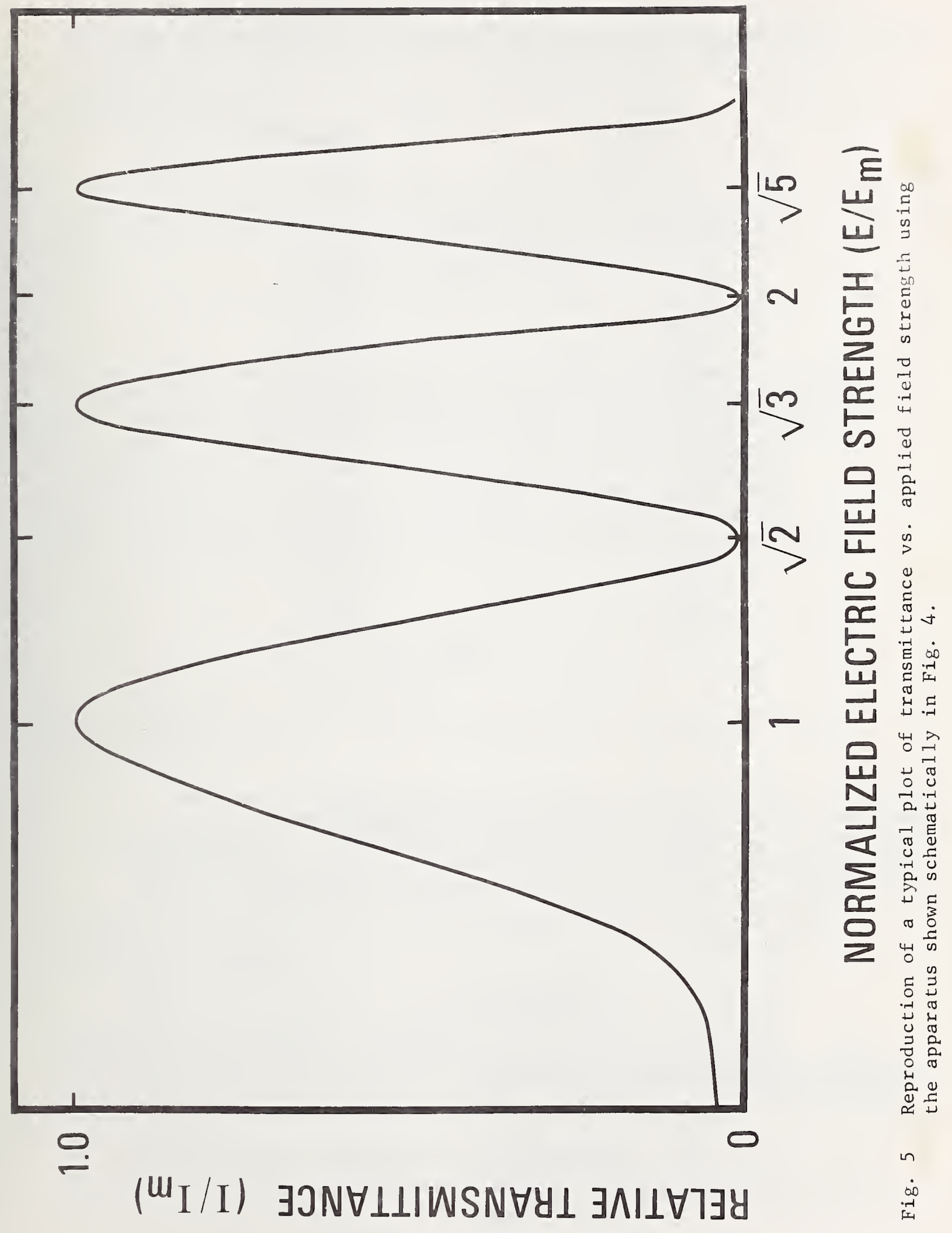


Table 4. Determination of the cell constant of a Halowax oil-filled cell under direct voltage.

\begin{tabular}{cc}
$\begin{array}{c}\text { Applied Voltage } \\
(\mathrm{kV})\end{array}$ & $\begin{array}{c}\text { Cell Constant } \mathrm{V}_{\mathrm{m}} \\
(\mathrm{kV})\end{array}$ \\
\hline 25.35 & 20.23 \\
27.30 & 20.15 \\
29.23 & 20.67 \\
31.80 & 20.18 \\
33.42 & 20.18 \\
34.94 & 20.18 \\
36.80 & 20.02 \\
38.27 & 20.00 \\
39.59 & 19.98 \\
39.94 & 19.97 \\
42.20 & 20.03 \\
44.81 & 20.04 \\
46.16 & 19.87 \\
48.10 & 19.92 \\
48.74 & 19.90 \\
50.68 & 19.93 \\
52.66 & 19.90 \\
55.24 & 19.94 \\
\hline
\end{tabular}

AVE 20.06

It can be noted from Table 4 that there are deviations from the average as large as $3 \%$. A deviation of this magnitude is to be expected for low values of the relative phase shift. To make explicit the relationship between the fluctuation in the determination of the cell constant $V_{m}$ and the value of the relative phase shift $\varphi$, recall

$$
V_{\mathrm{m}}=\mathrm{V} /(\varphi / \pi)^{1 / 2}
$$

Assuming all uncertainties are small,

$$
\frac{\Delta V_{m}}{V_{m}}= \pm \frac{\Delta V}{V} \pm \frac{1}{2} \frac{\Delta \varphi}{\varphi}
$$


In this discussion emphasis is placed on the contribution to the error caused by the uncertainty in phase shift. In these measurements the phase shift is not determined directly. The quantity measured is the transmittance, I/I , through the entire optical system. The relationship between an uncertainty in the phase shift and a measurement uncertainty in the transmittance $\triangle I / I_{m}$ is 14

$$
\frac{\Delta \varphi}{\varphi}=\frac{\cos ^{-1}\left\{(-1)^{n}\left(1-2\left[I / I_{m} \pm \Delta I / I_{m}\right]\right)\right\}-\cos ^{-1}\left[(-1)^{n}\left(1-2 I / I_{m}\right)\right]}{n \pi+\cos ^{-1}\left[(-1)^{n}\left(1-2 I / I_{m}\right)\right]}
$$

In Eq. 8, $\mathrm{n}$ is an integer defined by the relationship $\underline{\varphi}=\mathrm{n}+\alpha$ where $\alpha$ is the appropriate positive number between 0 and 1 . The response of Eq. 8 to variations in the parameters is not intultively obvious, but some predictions can be made without a full numerical solution. For example, it borders on the trivial to note that for a detection system to exist at all it must distinguish between minimum and maximum transmittance. That implies the numerator has a maximum value of $\pi / 2$ while the minimum value of the denominator is $n \pi$. The worst case uncertainty is then

$$
\frac{\Delta \varphi}{\varphi}=\frac{1}{2 \mathrm{n}}
$$

This is the basis for much of the previous work in which $\mathrm{n}$ was large so that

$$
\frac{1}{2} \frac{\Delta \varphi}{\varphi} \ll \frac{\Delta V}{V}=0.01
$$

If this be the case, it can be seen from Eq. 7 that the uncertainty in the determination of the cell constant is due to the uncertainty in voltage measurement.

In a previous report ${ }^{7}$ a system was described in which the transmittance maxima were counted during the high voltage pulse. This is equivalent to saying that the numerator of Eq. 8 can be as large as $\pi / 4$. $\mathrm{Eq} .8$ then predicts that for $\mathrm{n}>25, \frac{\Delta \varphi}{\varphi}<0.01$ which is in good agreement with the reported theoretical and experimental performance of that system.

In contrast with previous work, the variation in the observations listed in Table 4 is primarily due to $\Delta \varphi / \varphi$. It is estimated that for the 
measurement of high direct voltage $\Delta V / V$ is no larger than 0.001 . In the course of these measurements $n$ ranged from 1 to 7 . The primary source of error was, therefore, uncertainty in the measurement of the transmittance, $\Delta I / I_{m}$, a quantity which was safely ignored in previous measurements.

Although systematic analysis of the contributions to the quantity $\triangle I / I$ will be completed during the present fiscal year, the following contributions were identified during the course of this measurement:

1) Precision of the simultaneous measurement of specific values of $\mathrm{V}$ and $I / I_{m}$,

2) Nonlinearities in the detector-amplifier system and,

3) Fluctuations in the laser output.

A discussion of the total estimated uncertainty is included after the data taken under all three types of waveform are presented.

Typical data taken under $60 \mathrm{~Hz}$ alternating voltage are presented in $\mathrm{Tab} l e \mathrm{e}$.

Table 5. Determination of the cell constant of a Halowax oil-filled cell under alternating voltage.

\begin{tabular}{cc}
$\begin{array}{c}\text { Peak of the Applied } \\
\text { Voltage }(\mathrm{kV})\end{array}$ & $\begin{array}{c}\text { Cel1 } \begin{array}{c}\text { Constant } \\
(\mathrm{kV})\end{array} \\
\mathrm{m}\end{array}$ \\
\hline 23.57 & 20.25 \\
25.55 & 20.25 \\
32.36 & 20.23 \\
33.08 & 20.42 \\
37.37 & 20.13 \\
37.69 & 20.15 \\
42.57 & 20.07 \\
42.62 & 19.85 \\
42.63 & 20.06 \\
43.06 & 20.45 \\
46.88 & 19.99 \\
46.88 & 19.84 \\
50.73 & 20.01 \\
50.79 & 19.96 \\
54.74 & 19.85 \\
\hline
\end{tabular}

AVE 20.10 
The measurement technique employed was to use a capacitive divider to produce a low voltage replica of the applied waveform and to use a slideback technique to measure the peak value of an individual positive half-cycle. The Kerr response during that half-cycle was recorded in conventional manner. Again in this case $n$ ranged from one to seven so the errors associated with a small value of the phase shift apply to these as well as direct voltage measurements.

Under pulsed voltages a cell constant $19.87 \mathrm{kV}$ was obtained. The calibration was performed as described in section II of this report. Because there is a much smaller chance for self-heating or electrical breakdown during a $10 \mu \mathrm{s}$ pulse, the calibration was performed with a nominal applied voltage of $75 \mathrm{kV}$ peak.

In summary, the average values of the cell constants were

$\begin{array}{ll}\text { direct voltage } & 20.06 \mathrm{kV} \\ 60 \mathrm{~Hz} & 20.10 \mathrm{kV} \\ \text { pulse } & 19.87 \mathrm{kV}\end{array}$

It should be noted that the low frequency determinations are within $1.2 \%$ of the value determined under pulse conditions.

The variation within each of the low frequency sets of data is such that no reading differed from the average by more than $\pm 3 \%$. This consistency and the agreement among the three sets of data suggest that the uncertainty in each of the low frequency measurements is of order a few percent. It is therefore reasonable to refine this approach toward a definitive determination of whether or not a Halowax oilfilled cell can be calibrated at low frequency for use in the measurement of pulses.

The specific modifications of the apparatus that are being developed are

1) Replacement of $\mathrm{x}-\mathrm{y}$ recorder by a data acquisition system so that more precise values of $V$ and $I / I$ may be recorded. It is anticipated that this system will be applicable to tests under both direct and low frequency alternating voltage.

2) Development of appropriate electronic circuitry so that ratio of the laser's irradiance to the transmittance of the optical system can be detected. This should minimize the effect of fluctuations in the output of the laser.

3) Use of neutral density filters to calibrate the linearity of detector amplifier system. 
4) Incorporation of a thermocouple into the grounded electrode. This will reduce the thermal time constant of the temperature measurement system and will permit accurate measurement of the temperature in the interelectrode region.

5) Quantification of the effects of space charge in Halowax oil by careful mapping of the interelectrode field. With the limited sensitivity available, no effects were detected in the reported set of measurements.

C). Temperature Dependence of the Kerr Coefficient of Nitrobenzene.

Recall that the relationship between the cell constant and the Kerr coefficient is given by

$$
\left.\mathrm{V}_{\mathrm{m}}=\mathrm{d}(2 \mathrm{Bl})^{\prime}\right)^{-1 / 2}
$$

Taking the partial derivitive of this with respect to temperature yields

$$
\frac{1}{V_{m}} \frac{\partial V_{m}}{\partial T}=\frac{1}{d} \frac{\partial d}{\partial T}-\frac{1}{2 B} \frac{\partial B}{\partial T}-\frac{1}{2 l^{\prime}} \frac{\partial l^{\prime}}{\partial T}
$$

Note that the terms containing $d$ and $l^{\prime}$ are in the form of the coefficient of linear expansion. Because the cells are constructed of glass and metal, these two terms would be expected to be of order $10^{-5} /{ }^{\circ} \mathrm{C}$. Previous measurements have, however, indicated that near room temperature

$$
\frac{1}{\mathrm{~B}} \frac{\partial \mathrm{B}}{\partial \mathrm{T}} \approx 10^{-2} /{ }^{\circ} \mathrm{C}
$$

So, to within the limit of measurement accuracy, the temperature variation of the cell constant is reflective of the variation of the Kerr coefficient. If the cell constant of a cell is known at one temperature, $\mathrm{T}_{0}$, the following relationship can be used to calculate the cell constant at another temperature, $\mathrm{T}$ : 


$$
\mathrm{V}_{\mathrm{m}, \mathrm{T}}=\left(\mathrm{B}_{\mathrm{T}_{0}} / \mathrm{B}_{\mathrm{T}}\right)^{1 / 2} \mathrm{v}_{\mathrm{m}, \mathrm{T}_{0}}
$$

It therefore follows that a knowledge of the temperature dependence of the Kerr coefficient of nitrobenzene can serve to correct observations made using any similarly constructed, nitrobenzene-filled cel1.

The temperature dependence of the Kerr coefficient of nitrobenzene had been measured previously and the following values of the constants, as defined by $\mathrm{Eq} .5$, were obtained:

$$
\begin{aligned}
& A_{0}=4.44 \times 10^{-11} \mathrm{~m} / \mathrm{V}^{2} \\
& A_{1}=-2.86 \times 10^{-8} \mathrm{Km} / \mathrm{V}^{2} \\
& A_{2}=4.85 \times 10^{-6} \mathrm{~K}^{2} \mathrm{~m} / \mathrm{V}^{2}
\end{aligned}
$$

These constants were calculated from a least squares $\mathrm{fit}^{15}$ to the experimental data over a temperature range from $296 \mathrm{~K}$ and $305 \mathrm{~K}$.

Within the present contract period, data were taken over a temperature range from $286 \mathrm{~K}$ to $314 \mathrm{~K}$, thus extending the total range of measurement from about ten degrees to about thirty degrees. These more recent data were fitted to the same polynomial and the following constants determined the best fit

$$
\begin{aligned}
& A_{0}=2.546 \times 10^{-11} \mathrm{~m} / \mathrm{v}^{2} \\
& A_{1}=-1.717 \times 10^{-8} \mathrm{Km} / \mathrm{V}^{2} \\
& A_{2}=3.136 \times 10^{-6} \mathrm{~K}^{2} \mathrm{~m} / \mathrm{V}^{2}
\end{aligned}
$$

Although there was no disagreement between the two data sets as large as $1 \%$ over the common temperature range, the change in the constants was significantly larger. The conclusion drawn from this observation is that values of the constants are appropriate for interpolation within the range of measured values; extrapolation beyond the range of measurements should be done only with the knowledge that there is a possibility of introducing substantial error. 


\section{D). Kerr Coefficient of Water}

The data presented in this section also formed a portion of the report NBS IR 74-544, which was prepared at the request of the U.S. Air Force. Both the U.S. Air Force and Sandia Corporation expressed interest in the electro-optical behavior of water and partially supported this phase of the work.

A flow chart showing the measurement strategy and the interrelationships between the various experimental techniques is shown in Fig. 6. The two-cell technique and the end-field free cell technique were described in detail earlier. The single cell technique refers to determination of the Kerr coefficient by a measurement of the voltage, geometry and phase shift and using Eq. I to calculate the Kerr coefficient. A modification of this approach was to measure the cell constant rather than the geometry directly. If two different liquids are used in the same cell, the following relationship is valid

$$
\left(\frac{V_{m l}}{V_{m 2}}\right)^{2}=\frac{B_{2}}{B_{1}},
$$

where the subscripts 1 and 2 refer to the two liquids.

This approach is convenient in that years of development have demonstrated that $V_{m}$ for a given cell can be determined with an uncertainty no larger than $\pm 1 \% .16$ If the Kerr constant of one substance is known, then the measurement of the cell constants of same cell containing first the known liquid then the unknown liquid provides a measure of the Kerr constant without the associated problems of geometrical measurement. This approach was used to determine the ratio of the Kerr coefficient of water to the Kerr coefficient of nitrobenzene.

The cells that were used in the two cell technique ${ }^{7}$ were used to determine the ratio of the Kerr constant of water to the Kerr constant of nitrobenzene by this single cell technique. The measurement involved determining the cell constant of the cell with longer electrodes when it was filled with nitrobenzene and when it was filled with water. Using Eq. 10, it was determined that

$$
\mathrm{B}\left(\mathrm{H}_{2} \mathrm{O}\right) / \mathrm{B}\left(\mathrm{C}_{6} \mathrm{H}_{5} \mathrm{NO}_{2}\right)=1.058 \times 10^{-2} \text {, at } 295.6 \mathrm{~K} \text {. }
$$

As a further check, it was decided to perform measurements of the Kerr coefficient of water using a plastic cell with electrodes having approximately a Rogowski profile. This would yield two different determinations of the Kerr constant. One would be from direct 


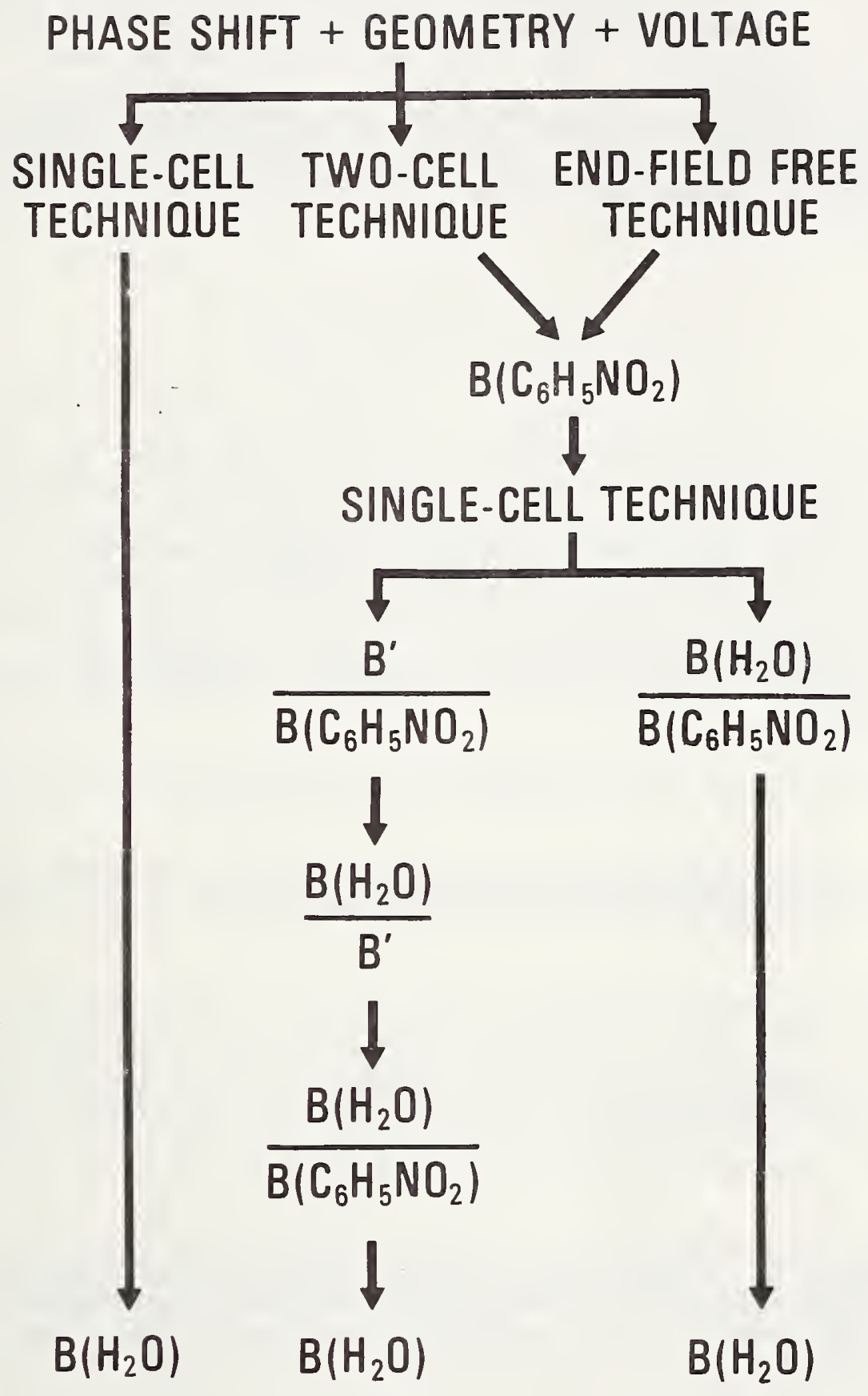

Fig. 6 Flow chart of the various measurements made of the Kerr coefficients of water, Halowax oil, and nitrobenzene. The Kerr coefficient of Halowax oil is denoted by $B^{\prime}$. 
measurements of the phase shift and geometry. The other would be a ratio measurement of the cell constant with water to the cell constant of nitrobenzene. Unfortunately, this latter technique could not be used directly because nitrobenzene, a good solvent, would destroy the structural integrity of the plastic cell. A two step procedure was then used. First, a glass cell was filled with nitrobenzene and its cell constant was measured. The cell was then filled with Halowax oil, and its cell constant determined. From these observations, the following ratio was obtained at $295.6 \mathrm{~K}$,

$$
\mathrm{B}^{\prime} / \mathrm{B}\left(\mathrm{C}_{6} \mathrm{H}_{5} \mathrm{NO}_{2}\right)=4.209 \times 10^{-2} \text {, }
$$

where $B^{\prime}$ represents the Kerr coefficient of the Halowax oil. Halowax oil and water could both be used in the plastic cell to determine the ratio of their cell constants. The procedure used in this case was to fill the cell with water (water used was the house distilled water), seal the cell, and determine its cell constant. Through a small hole in the top of the cell, the water was then pumped out, the cell was dried and filled with Halowax oil. This procedure was adapted to insure that the plate spacing remained unchanged during the refilling process.

Using this technique, the following ratio was obtained at $275.6 \mathrm{~K}$,

$$
B\left(\mathrm{H}_{2} \mathrm{O}\right) / \mathrm{B}^{\prime}=0.2499 \text {. }
$$

So,

$$
\mathrm{B}\left(\mathrm{H}_{2} \mathrm{O}\right) / \mathrm{B}\left(\mathrm{C}_{6} \mathrm{H}_{5} \mathrm{NO}_{2}\right)=1.052 \times 10^{-2}
$$

at $275.6 \mathrm{~K}$.

It should be noted that the two single cell techniques yield results differing by less than $0.6 \%$. The Kerr constant of nitrobenzene at $295.6 \mathrm{~K}$ is $3.26 \times 10^{-12} \mathrm{~m} / \mathrm{V}^{2}$. The two corresponding values of $\mathrm{B}\left(\mathrm{H}_{2} \mathrm{O}\right)$ are

$$
\mathrm{B}\left(\mathrm{H}_{2} \mathrm{O}\right)=3.45 \times 10^{-14} \mathrm{~m} / \mathrm{V}^{2}
$$


and

$$
\mathrm{B}\left(\mathrm{H}_{2} \mathrm{O}\right)=3.43 \times 10^{-14} \mathrm{~m} / \mathrm{V}^{2}
$$

From the cell constant and the geometry of the plastic cell an additional value of the Kerr coefficient of water can be derived. For a central path, the following relationship has been predicted ${ }^{17}$

$$
\ell^{\prime}=\ell+\frac{d}{\pi}
$$

Inserting this into $\mathrm{Eq} \cdot 3$, yields

$$
B=\frac{1}{2(l+d / \pi)}\left(\frac{d}{V_{m}}\right)^{2}
$$

In this case $\ell=0.2998 \mathrm{~m}, \mathrm{~d}=6.32 \times 10^{-3} \mathrm{~m}$ and $\mathrm{V}_{\mathrm{m}}=44,010 \mathrm{~V}$. So,

$$
B=3.42 \times 10^{-14} \mathrm{~m} / \mathrm{v}^{2} \text {. }
$$

The close agreement among these three values is thought to be serendipity, because the estimated uncertainty in these measurements is $\pm 7 \%$.

An additional source of error was Identified during the course of these investigations. Under microsecond duration pulses the water was occasionally in turbulent motion sufficient to modulate $I_{m}$, the maximum transmitted irradiance. This is in marked contrast to experience by the authors with nitrobenzene and Halowax oil in which no turbulence is detected under high voltage pulses of this duration.

Previous results ${ }^{6}$ have indicated that accurate Kerr measurements can be made even in the presence of turbulent motion. This was true because in that case the ratio of the amount of scattered light to the amount of transmitted light was undetectably small with the apparatus used. A second effect occurs, however, when the scale of turbulent motion is of order the size of the light beam. In this situation the fluid motion causes density gradients in the fluid. The density gradients lead to a change in the index of refraction which serves to deflect the light beam. As a consequence, the light beam "wanders" across the photo-sensitive surface of the detector. Because of spatial variations in quantum efficiency of the detectors used and/or because 
of the fact that a portion of the light beam may miss the photosensitive surface altogether, the photocurrent is amplitude modulated. This leads to an envelope on the Kerr response and was first detected in this study as an apparent voltage dependence of the cell constant. In this study the effects of fluid motion were minimized in three ways. First the distance between the photodetector and the Kerr cell was kept as short as possible. The other two approaches exploited the fact that this larger scale turbulence was apparently modified by the geometry of the cell. In the glass cell there was no detectable amplitude modulation during the first $6 \mu \mathrm{s}$ of the applied voltage pulse. Kerr constant measirements were then taken only during this relatively quiescent period. In the plastic cell the time interval between the rise of the voltage pulse and the onset of amplitude modulation could be varied by adjusting the water level in the cell. By a judicious choice of water level no amplitude modulation occurred during the entire 10 us voltage pulse.

A final word of caution is in order concerning the electric fiefd dependence of the Kerr coefficient of water. There is some evidence 18 that the dielectric constant of water 1 s $0.7 \%$ lower when measured at a field strength of $250 \mathrm{kV} / \mathrm{cm}$ than when measured in weak fields. The uncertainty in the present work precluded the observation of any corresponding saturation effect, but the possibility of saturation cannot be ignored if the present work serves as the basis of measurement of voltage at significantly higher field strengths.

IV. Electric Field Distributions and Space Charge Behavior in Nitrobenzene under Low Frequency Alternating Voltage

\section{A). Introduction}

The electro-optic Kerr effect has been used by a number of workers over the last two decades to measure the electric field distribution in a variety of liquids and to study the electric field distribution around solid insulators. Measurements have typically been either under direct or pulsed high voltage.

It has long been recognized that if one wanted to use the Kerr effect to measure the electric field distribution due to the geometry of his electrodes and/or insulator forms he had two choices. Either he could perform the measurement under pulsed voltage or, alternatively, could carefully purify his liquid, coat the electrodes with an appropriate membrane and, if he confined himself to moderate field strengths, could be fairly certain that observed distortions were a result of geometry and not due to a property of the Kerr fluid itself. If uncoated electrodes or higher field strengths were used the electric field in the Kerr liquid would be distorted. Historically, depending on the materials and their state of purity, this distortion has been attributed to chemical or electromchemical processes either in the bulk or at the electrode surface or to the presence of suspended particles in the bulk of the fluid. 
It was judged that an understanding of the dynamics of this distortion could lead to more accurate voltage measurement using the electro-optic Kerr effect and to additional understanding of electrical conductivity and breakdown phenornena in insulating liquids. We therefore measured the electric field as a function of position and time under direct and low frequency alternating voltage in a nitrobenzentu filled parallel-plate capacitor.

The data presented here were taken in a cell having nickel electrodes. The nitrobenzene was purified before it was sealed into the cell. The measured resistivity was of order $10^{10}-10^{11} \Omega \mathrm{cm}$.

\section{B). Experimental Results}

The experimental apparatus consists of a nitrobenzene-filled parallel-plate capacitor, a triggerable pulsed argon laser, crossed polarizers oriented at + and $-45^{\circ}$ to the interelectrode field direction, and appropriate photographic equipment for recording of the transmitted fringe patterns observed when the laser is flashed during high voltage operation. The laser beam is expanded and collimated to illuminate the area between and around the test cell electrodes. During direct voltage studies, the high voltage was connected to a parallel corbination of the test cell and a calibrated $100 \mathrm{M} \Omega$ resistive divider. For current measurements a microammeter was placed in series with the Kerr cell between the cell and ground. For ac studies, the power-amplified output of an audio oscillator supplied a step-up transformer. The transformer's output voltage was applied to one electrode of the cell, the other electrode of the cell being grounded. The rms values of the applied voltage was measured using a 1000:1 metering tap on the transformer.

The governing equation ${ }^{5}$ for the analysis of data obtained is

$$
\left(I / I_{m}\right)_{x, t}=\sin ^{2}\left[\frac{1}{2} \pi\left(\bar{E} / \bar{E}_{\text {I }}\right)_{x, t}^{2}\right]
$$

In this expression I is the irradiance of the transmitted light, I is the maximum irradiance, $E$ is the electric field magnitude, $E$ is the electric field necessary to produce the first maximum in the transmitted irradiance and the overbar (e.g., in A) denotes

$$
\bar{A}=\left[\frac{1}{L} \int_{0}^{L} A^{2} d z\right]^{1 / 2}
$$


where $L$ is the geometrical length of the optical path through the applied field. It should also be noted that the subscripts $x, t$ indicate the time and position at which the data were taken and that we are assuming a coordinate system in which the light beam propagates in the $\mathrm{z}$-direction, and the $\mathrm{x}$-direction is perpendicular to and the $y$-direction parallel to the surfaces of the electrodes. We have analyzed data only at a specific value of $y$, the geometric center of the electrodes.

Fig. 7 shows the relative electric field as a function of position under direct voltage. In order to determine the space charge density a linear fit (least squares) was performed. From the data presented the calculated space charge density ranges from $4 \times 10^{-8}$ to $14 \times 10^{-8} \mathrm{C} / \mathrm{cm}^{3}$. It is noted that the space charge density observed here agrees well with similar data obtained, using the electro-optic Kerr effect, with a chlorobiphenyl as the insulating liquid ${ }^{19}$. In that case it was postulated "that the space charge... is due to the dissociation of the $\mathrm{H}_{2} \mathrm{O}$ molecule and consists largely of $\mathrm{H}^{+}$ions." Even though there is good agreement in both magnitude and sign it is thought that in the present work the generation of the space charge is dominated by electrode surface rather than fluid bulk phenomena. This conclusion is based on the behavior under low frequency alternating voltage which will be discussed later in the paper.

Three trends were identified from this and similar data. First, the net charge was always positive and uniformly distributed in the bulk. Second, the space charge density decreased as the voltage level was increased, and, third, the net charge in the liquid was slightly greater when negative high voltages were applied.

The situation was radically different, however, when alternating voltage was applied. In Fig. 8 is plotted the relative electric field strength as a function of distance from the high voltage electrode at various instants during the cycle of a $20 \mathrm{kV}$ rms, $60 \mathrm{~Hz}$ applied voltage waveform (plate spacing $0.5 \mathrm{~cm}$ ). These data were taken by synchronizing a pulsed laser (light pulse width $\simeq 6 \mu \mathrm{s}$ ) with the applied voltage waveform so that the electric fleld distribution was strobed at a preselected, adjustable time during the cycle. It can be seen from Fig. 8 that as one progresses through one cycle of the applied voltage (of perfod $T$ ) a field distribution indicative of homocharge is first produced $^{20}$. Soon after the peak of the positive half-cycle the field becomes uniform. The field distribution then inverts and assumes a distribution characteristic of heterocharge. Fig. 9 shows similar observations in the same cell made at selected instants during the cycle of $16 \mathrm{kV}$ rms applied voltage at 60 and $120 \mathrm{~Hz}$. In contrast with the previous figure, there is no longer evidence of an electric field distribution attributable to heterocharge. [Note that in this context the words heterocharge and homocharge are used only to describe the relationship between the polarity of the electrode and the net charge near it. They do not imply any mechanism of charge production or transport]. It was also observed in this work that the electric field 


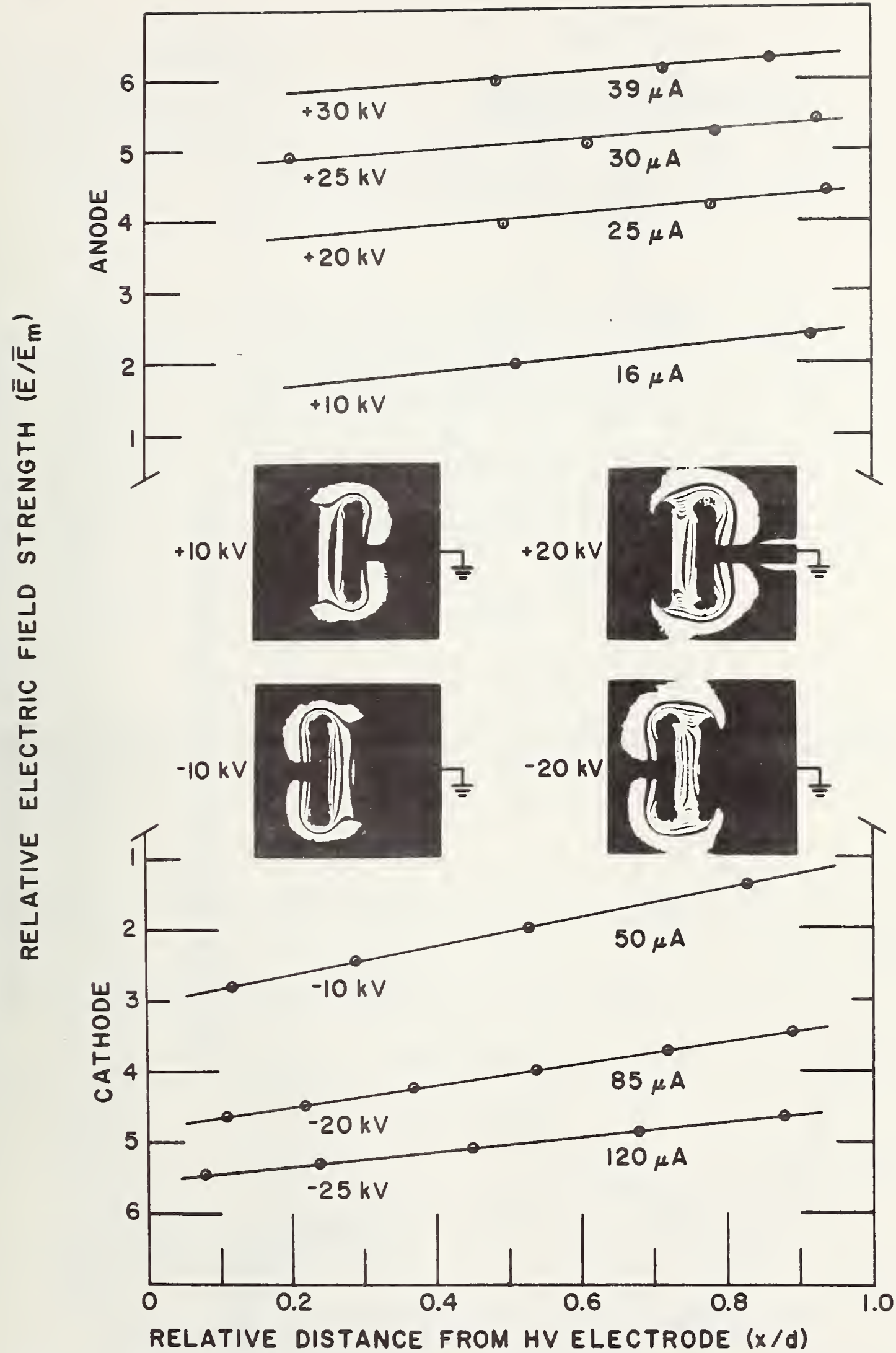

Fig. 7 Typical field distribution data under direct voltage. Photographs from which some of the data were taken are presented in the center of the figure. 


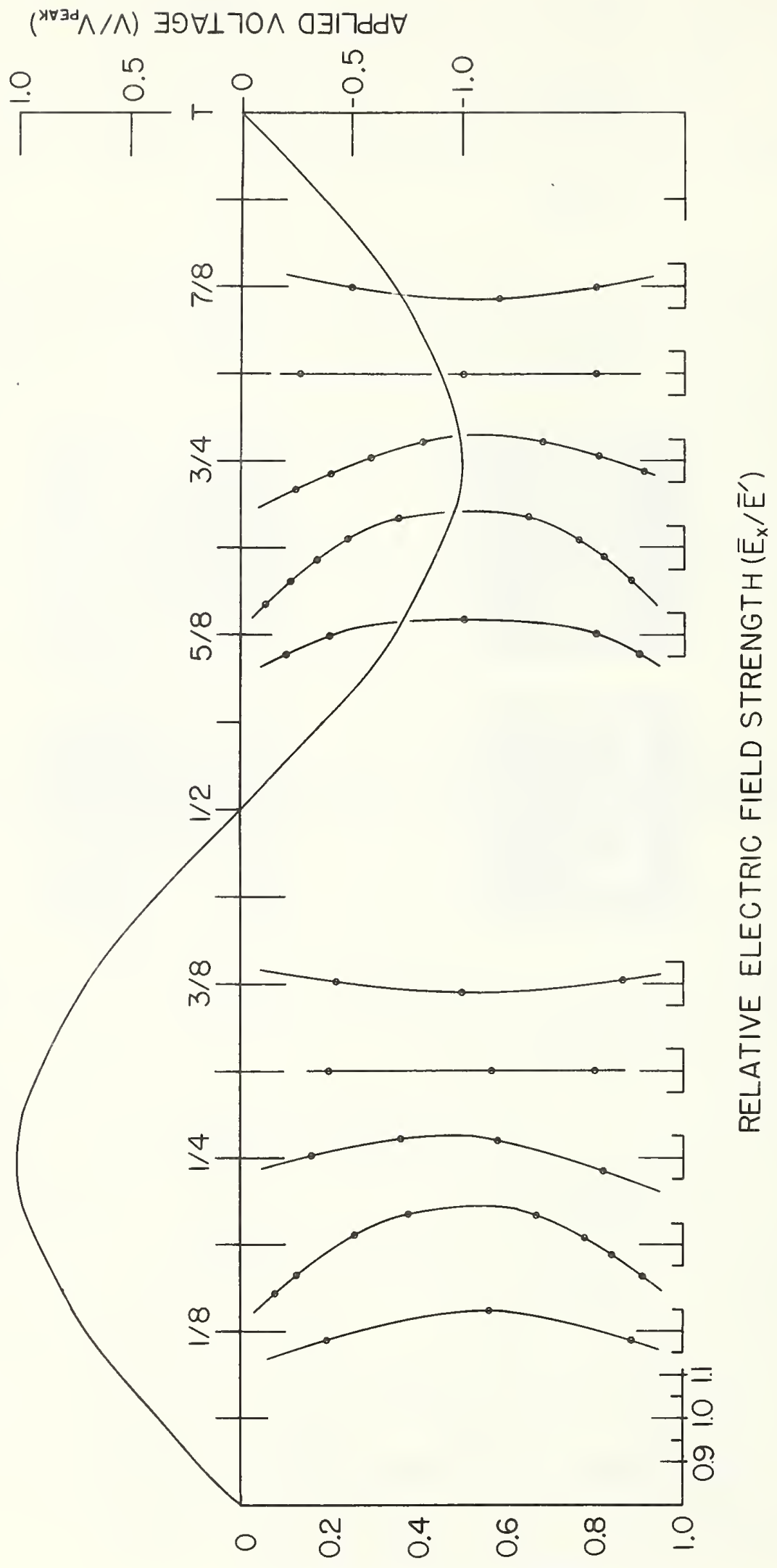

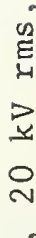

ำ

8

$4-1$

(1)

U.

()

ᄂ

我

.

资

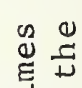

넌

วิ

당

$\stackrel{\pi}{>}$

$+\infty$

$\pi$

동

गิ

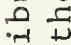

id 0

可的

$\underset{.1}{0}$

$x_{4-1}^{-1}$

บ

넌

व

点点

$\infty$

$\infty_{\substack{\infty \\ x-1}}^{\infty}$

$(P / x) \exists 0 O 4 \perp 0 \exists 7 \exists \wedge H$ WOy 1 ISIO 


\section{$60 \mathrm{~Hz}$}

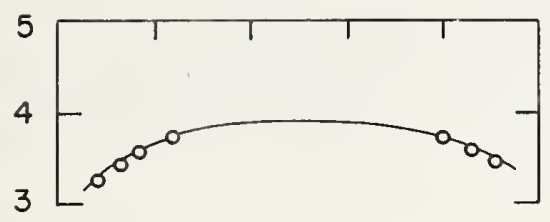

$120 \mathrm{~Hz}$

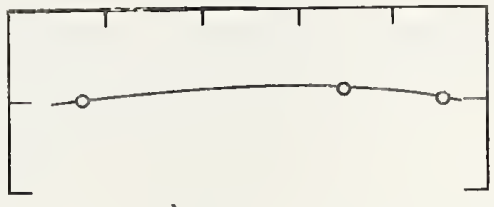

$3 / 16 T$

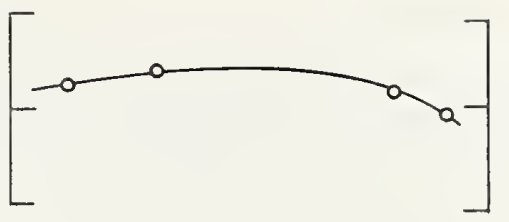

$1 / 4 T$

$3 / 8 T$

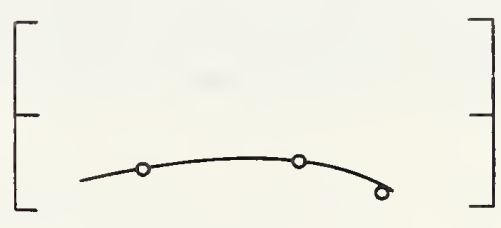

5/8 T

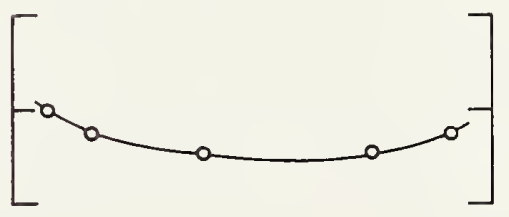

$3 / 4 T$

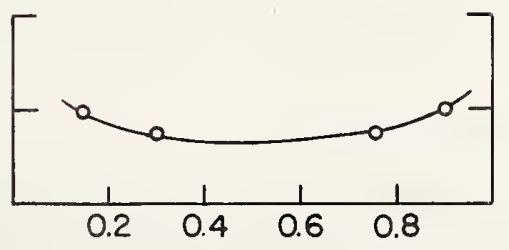

\section{RELATIVE DISTANCE FROM HV ELECTRODE $(x / d)$}

Fig. 9 The electric field distributions at corresponding times during 60 and $120 \mathrm{~Hz}, 15 \mathrm{kV}$ rms, applied voltage. 
distortion was approximately constant in the range from 60-120 $\mathrm{Hz}$, with measurements being performed at $60,80,100,120 \mathrm{~Hz}$. At higher and lower frequencies there was a trend toward reduction in the curvature in the distributions with limiting cases being a uniform field under short pulse conditions and a field which is approximately a linear function of position under direct voltage.

\section{C). Discussion}

There is qualitative agreement between the data and the assumption that there are particulate impurities in the system. If particulate impurities are present they are charged upon contacting an electrode. Once it leaves the initial electrode, the charge on any particle can decay due to fluid ohmic conditions. The critical parameter is the ratio of the electrical relaxation time, $\varepsilon / \sigma$, where $\varepsilon$ is the fluid permittivity and $\sigma$ its conductivity, to the transport time $d / U$, where $d$ is the electrode spacing and $U$ is the average particle velogity. The ratio of these times is called the electric Reynolds number

$$
R_{e}=(\varepsilon / \sigma) /(d / U)
$$

If $\mathrm{R} \sim 1$, the net charge distribution is the sum of two exponential distributions. The predicted result is negative charge near the cathode and positive charge near the anode. This is observed experimentally in almost all cases. The deviations from this behavior, shown in Fig. 8, may be attributable to the voltage dependence of $\mathrm{R}_{\mathrm{e}}$.

If $R_{e}>1$, the observed behavior can be understood in terms of the roll cell molel used by Felici ${ }^{13}$ and Thomas ${ }^{22}$. This model assumes that the charge carriers move with the fluid, from electrode to electrode, with a velocity $U$. The charge on each carrier is proportional to the electric field strength at the electrode at the time that the carrier is in contact with it. This predicts that as the voltage is increasing in magnitude there will be positive charge near the positive electrode and negative charge near the negative electrode. Sometime after the peak the field should become uniform. The reason that this heterocharge distribution was not observed in Fig. 3 may be that there was insufficient sensitivity at the low voltages.

\section{D). Conclusions}

It has been shown that the electric field distribution and, consequently, the space charge distribution, in a liquid insulant are different under direct and low frequency alternating voltage and that both differ from ideal distribution predictable from geometry. It has been recently shown that in commercfil insulating liquids the breakdown is controlled by spazce charge ${ }^{9}$. For lack of more substantial information however, authors ${ }^{23}$ have obtained the breakdown field 
strength at $60 \mathrm{~Hz}$ in an insulating liquid by measuring the breakdown voltage and calculating field from the electrode geometry. It is shown here that even with plane parallel electrodes the field can differ markedly from the ideal case because the electric field in a liquid insulator is defined by both the electrode geometry and by the space charge dynamics within the fluid.

\section{Acknowledgements}

The authors would like to acknowledge collaboration with Dr. Markus Zahn of the University of Florida during some of the investigations reported in Section IV of this report. In addition, the authors would like to thank those who assisted in the experimental investigations especially Mr. William A. Bagley for assistance in construction and operation of the apparatus and Miss June Jones for assistance in accumulation and analysis of the data. Finally, those who assisted in the preparation of the manuscript should be recognized, particularly Mrs. Mary Cutkosky who prepared the graphics and Miss J. Cunningham for the editorial and typographical assistance she provided. 
APPENDIX A

KERR-EFFECT STUDIES OF AN INSULATING LIOUID UNDER VARIED HIGH-VOLTAGE CONDITIONS

This material was published in the IEEE Transactions on Electrical Insulation, vol. EI-9, pp. 43-56, 1974. 


\title{
Kerr-Effect Studies of an Insulating Liquid Under
}

\section{Varied High-Voltage Conditions}

\author{
ESTHER CHRISTMAS CASSIDY, SENIOR MEMBER, IEEE, ROBERT E. HEBNER, JR., MEMBER, IEEE, \\ MARIUUS ZAHN, MEMBER, IEEE, AND RICHARD J. SOJKA, STUDENT MEMBER, IEEF.
}

\begin{abstract}
Refined Kerr electrooptical fringe-pattern methods are used to study time and space variations in the electric field between the electrodes of parallel-plate capacitors filled with liquid nitrobenzene. Photographs of fringe-pattern data recorded during application of high direct (both positive and negative) and sinusoidal voltages, ranging in frequency from 40 to $200 \mathrm{~Hz}$, are compiled to enable computation of space-charge distortions of the field in bulk of the liquid during the stress of high-field (up to $85-\mathrm{kV} / \mathrm{cm}$ ) operation. The measurements reveal significant differences between the field and charge behavior under short pulse (microsecond) voltage conditions, during prolonged dc operation, after sudden changes in the dc voltage level and polarity, and, for the first time, at various intervals over the course of entire cycles of sinusoidal voltage. The results show that space-charge distortion in the interelectrode field is influenced by the level, frequency, and duration of applied voltage. Discussions of effects believed due to particulate charge carriers, to electrohydrodynamic motion of the liquid, and to the electrode materials are also included.
\end{abstract}

\section{INTRODUCTION}

$\mathbf{R}^{\mathrm{F}}$ ECENT WORK has experimentally demonstrated the usefulness of the electrooptic Kcrr effect for the determination of various electrical parameters under the influence of high voltage. Among these are the measurement of pulsed high voltage $[1]-[4]$, the determination of space-charge effects in nitrobenzene [5]-[6] and chlorinated biphenyls [7], the measurement of the electric-field distortion caused by the insertion of a solid dielectric in a liquid insulant [8], the measurement of $60-\mathrm{Hz}$ alternating voltages [9], and the observation of the spatial and temporal variation of the electric-field distribution caused by pulsed and direct voltage [10][12]. In addition, theorctical advances in the understanding of space-charge phenomena in insulating liquids have been made in such areas as the prediction and description of bulk space charge [13] and polarization waves [14] in charged-liquid systems and the role of particulate charge carriers in electrical conductance [15].

Realizing that further advances are predicated on a knowledge of electric-field and space-charge behavior in

Manuscript received September 21, 1973. This work was supported in part by the U. S. Atomic Energy Commission through the Sandia Corporation, Albuquerque, N. Mex. One of the nuthors (II. Zahu) received partial support from the National Science Foundation under Grants GK-27803 and GK-37594.

E. C. Cassidy, R. E. Hebner, Jr., and R. J. Sojka are with the Electricity Division, National Bureau of Standards, Washington, D. C. 20234 .

M. Zahn is with the Department of Electrical Engineering, University of Flon ida, Gainesville, Fla. 32601. liquid dielcetrics, we have used refined Kerr electrooptical fringe-pattern techniques $[10]-[11]$ to measure and compare electric-field and charge distributions in nitrobenzene-filled parallel-plate capacitors during pulsed, direct, and low-frequeney alternating high-voltage operation. The purpose of this work, which supplements the substantial quantity of data published from earlicr nitrobenzene studies, is the determination of, and ultimatcly control of, the complex mechanisms that lead to electrical breakdown in insulating liquids. The present work was also undertaken partly to incrcase the precision of $60-\mathrm{Hz}$ voltage measurements. The results demonstrate both the feasibility and the effectiveness of using elertrooptical fringe-pattern techniques to visualize electric-field distributions and space-charge behavior under steady-state alternating high voltages. Field strengths as high as 85 $\mathrm{kV} / \mathrm{cm}$ are applied. The effects of voltage level and frequency on space-charge density and distribution are investigated between 0 and $\pm 50 \mathrm{kV}$; frequencies range from 40 to $200 \mathrm{~Hz}$.

Nitrobenzene is the liquid investigated, primarily because of its high electrooptical coefficient (of order $10^{-12}$ $\mathrm{m} / \mathrm{V}^{2}$ ) and relatively high clectrical breakdown strength $(>100 \mathrm{kV} / \mathrm{cm})$. Though its powerful solvent, hygroscopic, and toxic properties make this liquid impractical for many insulating applications, nitrobenzene is uniquely suited to serve in this capacity for a multiplicity of diverse specialized applications, ranging from its use as the dielectric in prototype "high-energy" electrostatic generators [16] to its widespread use in high-spced photographic shutters [17] and laser "Q-switching" devices [18], to its use for precision mcasurements of pulsed high voltages. In connection with the latter application, extensive studics, now underway for more than five years, of the performance of nitrobenzene-filled Kerr cells immersed in oil under both transient (microsecond pulses) and steady-state dc and ac operation have demonstrated that the physical behavior of nitrobenzene under high-field conditions is cssentially the same as that of most insulating liquids. Its conductivity and breakdown strength are, for example, affccted by space-charge effects [19], whether they result simply from moisture, impurities, and particulate contaminants in the liquid, or from more complex mechanisms such as charge formation by electrochemical reaction or field emission at the electrodes. Its performance is also affected by other widely reported high-field phenomena [20] such as electrohydro- 


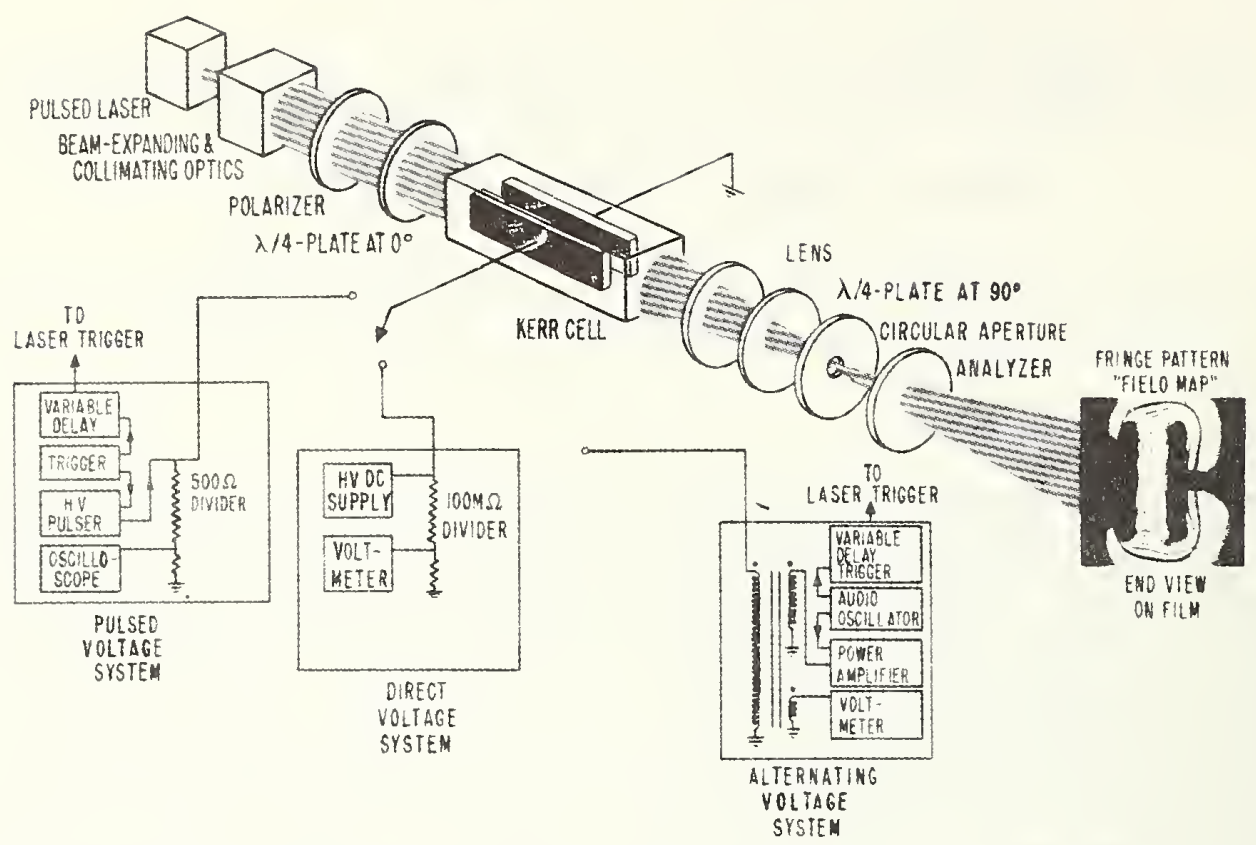

Fig. 1. Schematic diagram of the apparatus used to measure the electric-field distributions in nitrobenzene. Typical Kerr-effect fringe pattern is shown on the right of the drawing. The systems used to supply and measure the applied voltage are also shown.

dynamic motion, bubble formation, electrophoretic and dielectrophoretic forces, the Sumoto effect, etc. All of these phenomena are known to be more or less pronounced depending upon the condition of the liquid, the electrode design, the nature and level of applied voltage, etc. Yet our understanding of electric-field and charge behavior, and thus of breakdown, in the bulk of insulating liquids remains admittedly poor.

It has been our philosophy in the preparation of this paper that much is to be gained from careful analysis of electrical stress and space-charge behavior which can be so easily observed experimentally in nitrobenzene by use of Kerr-effect fringe-pattern techniques. Although the chemical composition of nitrobenzene differs significantly from that of more commonly used insulating fluids, it is reasonable to expect that behavior attributable to physical phenomena, such as conduction by particulate impurities or electrohydrodynamic motion of the liquid, is similar in both cases. Accordingly, more than 600 individual experiments investigating such behavior were performed with sealed nitrobenzene-filled cells under a variety of carefully monitored high-voltage conditions. The results demonstrate significant differences between the pulsed and steady-state ac or de field and charge behavior in the bulk of the liquid. Whereas expected conditions were observed during short pulse operation, several significant unforeseen trends were observed in the steady-state experiments, thereby pointing up the fact that extrome care should be exereised in inferring behavior at power-line frequency from characteristics observed under de or puised-roltagr operation. If, for rxample, it is suspected that the degradation of an insulating liquid is due to the presence of space charge, whether formed chemically or carried by particulate impurities, the data presented here suggest questioning of the common practice of inferring the liquid's performance at power frequency from accclerated aging (for shorter times at frequencies much higher than $60 \mathrm{~Hz}$ ) testing or de testing results.

The experimental techniques and methods of data analysis employed in the present work are described in Sections II and III, respectively. Section IV presents and discusses the data obtained under direct voltage and under alternating voltages. The final section, Section $\mathrm{V}$, presents the summary and conclusions.

\section{EXPERIMENTAL APPARATUS AND TECHNIQUES}

A sehematic diagram of the experimental apparatus is given in Fig. 1. The system consists of a nitrobenzenefilled parallel-plate capacitor within a glass vessel (Terr cell), a triggerable pulsed argon laser, crossed polarizers oriented at + and $-45^{\circ}$ to the interelectrode-field direction, retardation plates oriented as indicated for elimination of field-directional fringes [21] not pertinent in the present work, and appropriate photographic equipment for recording of the transmitted fringe patterns observed when the laser is flashed during high-voltage operation. The laser-beam diameter is expanded and collimated as indicated to illuminate the area between and around the test-call electrodes. The beam is focused and passed through the circular aperture to exelude extraneous reflections and, on occasion, to allow Schlieren observations of the liquid motion invariably produced by steady-stat high-voltage operation. For purposes of illu-tration. the diagrani includes a typical fringe pattern photographed 
by flashing the laser with $-20-\mathrm{kV}$ de applied to the test cell. During such direct voltage studies, the high voltage $(0- \pm 50 \mathrm{kV})$ was connected to the parallel combination of the test cell and a calibrated 100- $M \Omega$ resistive divider [22] as shown. The divider was used to measure the high voltage across the ecll. For current measurements a microammeter was placed in series with the Kierr cell, between the cell and ground.

For the ac studies, alternating high voltage was obtained by amplifying the output of an audio oscillator. This power-amplified signal supplied a step-up transformer, and the latter's output voltage, as high as $40 \mathrm{kV}$ rms with frequencies over the range from 40 to $200 \mathrm{~Hz}$, was applied to one electrode of the cell, the other electrode being grounded. The rms value of the applied voltage was measured using a 1000:1 metering tap on the transformer.

In order to control the timing (during a cycle) of the ac fringe-pattern observations, triggering of the laser pulse (flash duration $\approx 6 \mu \mathrm{s}$ ) was synchronized with the high alternating voltage applied to the cell. This was accomplished by using the audio-oscillator output signal to trigger an oseilloscope equipped with a manually adjustable delayed-output voltage pulse for triggering of the laser pulse. The delay and synchronization of this delayed trigger signal were adjusted, Fig. 2, so that the laser flashed in a strobelike manner to allow discrete obscrvations of the fringe pattern at a sclected time(s) during a cycle. The time interval $\Delta t$ between the triggering of the oscilloscope and the triggering of the laser was monitored using a conventional counter which counted its internal

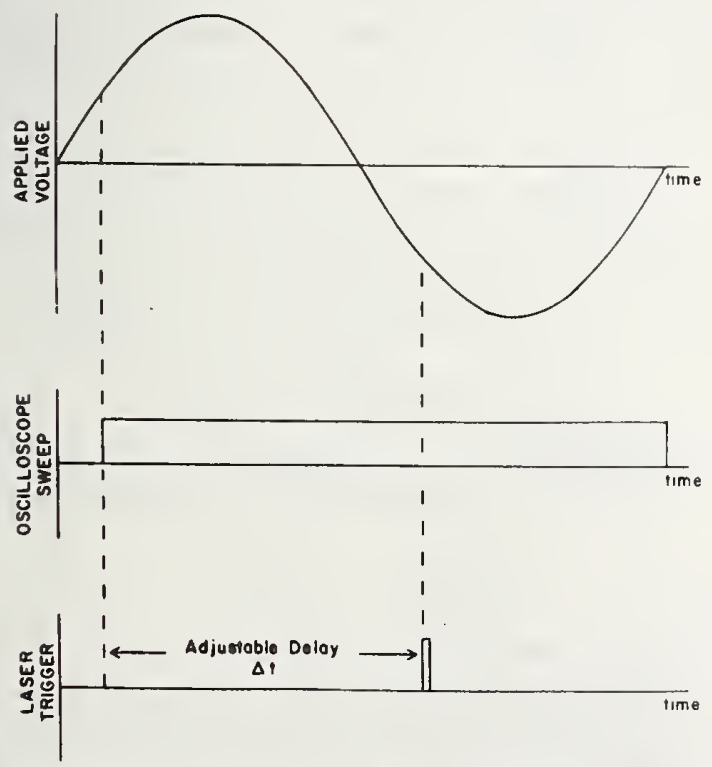

Fig. 2. Timing diagram of system used to observe the electric-field distribution at various instants of time during a cycle of alternating voltage. The upper trace shows one cycle of the applied voltage. The center trace represents the time for one sweep of the horizontal time base of the oscilloscope. The oscilloscope is externally triggered by the applied-voltage waveform. The bottom trace shows the laser trigger pulse. The delay between the start of the oscilloscope sweep and the laser trigger pulse is manually adjustable and the duration of the laser light pulse is of order $6 \mu \mathrm{s}$. clock pulses during $\Delta t$. In this way $\Delta t$ could bre very accurately measured. Two methods were used to correlate a value for the interval $\Delta t$ with a specific point during a cycle of the applied voltage. The first was to detect a portion of the laser light pulse with a photomultiplier and display the time relationship between the laser light pulse and the applied voltage on the oscilloseope sereen. The time interval $\Delta t$ was then adjusted until the light pulse coineided with the prak of the positive half-eycle. The second and somewhat more aecurate mothod was to adjust $\Delta t$ until the fringe pattern resulting from the rlectrooptic Kierr offect inclicated that the laser was pulsed at the prak of the positive half-eycle, i.e., until the number of fringes produced was maximum. All attempts to correlate a speeifie point on the applied-voltage waveform with a value of $\Delta t$ were reproducible to within $\pm 20 \mu \mathrm{s}$, i.e., to within \pm 0.8 poreent of the shortest half-cyele used.

The present work was conclucted using two specially prepared eells (see Table I). one with electropolished stainless-sted electrodes of dimensions $4 \mathrm{~cm}$ wide by 12 cm long, and the other with glass-blasted nickel electrodes of dimensions $2 \mathrm{~cm}$ wide loy $12 \mathrm{~cm}$ long. The electropolishing and glass-blasting procedures were adopted to minimize the effects of eleetrode-surface contamination. The electrode edges and eorners are rounded to avoid premature electrical breakdown. The nominal clectrode spacing in both eases is $0.5 \mathrm{~cm}$. Glass-to-metal scals are used for inserting tungsten rods which provide electrical connection and support for the electrodes. An expansion volume is included to prevent failure of the glass vessel when the test liquid expands due to heating. A thermometer is sealed into the nitrobenzene for monitoring of its temperature. (Temperature increases as large as $20^{\circ} \mathrm{C}$ were encountered during prolonged high-voltage ac operation.) External surface and air flashovers are avoided by immersing the test vessel in transformer oil. More complete details of our cell-construction technique were presented elsewhere [11].

With regard to the test-cell insulant, nitrobenzene was, as previously mentioned, selected primarily because of its high electrooptical coefficient and relatively high electrical breakdown strength. Though the electrical resistivity of commercially pure grades is inadequate (of order $10^{3} \Omega \cdot \mathrm{m}$ ) for steady-state high-voltage operation, increased resistivity is readily obtained by passing reagent-grade liquid through a chromatographic adsorption column of activated alumina. In the present work, this procedure, which has long been used to remove moisture and other impurities from insulating oils [23], increases the nitrobenzene's resistivity to the order of $10^{8}-10^{9} \Omega \cdot \mathrm{m}$. At this level, prolonged steady-state high-voltage de and ac operation could be maintained without excessive liquid heating or turbulence due to current leakage. Gas chromatographic analysis of the liquid before and after processing showed that, as is often the case with insulating oils, water is the principal contaminant. Thus, because of the hygroscopic and toxic properties of nitrobenzene, our entire cellfilling and sealing proceture is performed under vacuum. 
TABLE I

Parameters for the Test Vessels Described in the Text

\begin{tabular}{|c|c|c|c|}
\hline CELL & $\begin{array}{l}\text { ELECTRODE } \\
\text { MATERIAL }\end{array}$ & $\begin{array}{c}\text { ELECTRODE STRUCTURE } \\
\& \text { PREPARATION }\end{array}$ & $\begin{array}{c}\text { CLLL CONSTANT } \\
\left(\bar{E}_{\mathrm{m}} \mathrm{d}\right)\end{array}$ \\
\hline A & Nickel & $\begin{array}{l}\text { Parallel-plate } \\
\text { Glass-blasted }\end{array}$ & $4900 \mathrm{~V}$ \\
\hline$B$ & $\begin{array}{l}\text { Stainleas } \\
\text { Steel }\end{array}$ & $\begin{array}{l}\text { Parallel-plate } \\
\text { Electro-polished }\end{array}$ & $4600 \mathrm{~V}$ \\
\hline
\end{tabular}

Vote: The cell constants listed are valid for $514.5-\mathrm{nm}$ argon laser radiation at a liquid temperature of approximately $298 \mathrm{~K}$.

\section{THEORY}

Comprehensive theoretical discussions of the electrooptic Kerr effect, including derivations of the Kerr constant [24]-[26], the application of the Kerr effect to high-voltage measurement, and methods for eliminating the effects of fringing fields [27], are available in the literature. The purpose of this section is to make explicit the assumptions used in the analysis of the data presented. The governing equation for the Kerr effect is

$$
n_{11}-n_{\perp}=\lambda B E^{2}
$$

where $n_{11(1)}$ is the index of refraction for light polarized parallel (perpendicular) to the direction of the applied field $E$. The Kerr constant of the liquid is $B$ and $\lambda$ is the wavelength of the monochromatic light traversing the Kerr cell. Equation (1) can be solved for the phase shift, $\varphi$, between the components of the light beam polarized parallel to and perpendicular to the direction of the applied field

$$
\varphi=2 \pi \int_{0}^{L} E^{2} B d l
$$

In (2), $J_{\Delta}$ is the geometrical length of the optical path through the applied field. To reduce (2) to a more convenient form it is necessary to make a number of observations concerning the electric-field distributions in the cells used. To clarify this discussion, define a set of coordinate axes so that the $z$ direction is the direction of propagation of the light beam, the $x$ direction is perpendicular to, and the $y$ direction is parallel to the surface of the electrodes. In this notation (2) can be rewritten

$$
\varphi(x, y, t)=2 \pi \int_{0}^{L} B E^{2}(x, y, z, t) d z
$$

which also explicitly includes time dependence. The first assumption is that $B$ is a constant, so that

$$
\varphi(x, y, t)=2 \pi B \int_{0}^{L} E^{2}(x, y, z, t) d z .
$$

In the present work, all field mapping is done in the $x$ direction. We have therefore analyze data only at a specific value of $y$, the gemetric center of the electrodes. It is shown in our data and has been shown in previous studies in cells with similar geometry that $\varphi(y)$ varies only slightly near the center of the plates so that error in locating the exact center of the plates are negligible in comparison to other errors in the analysis. We can therefore rewrite $(2 b)$ as

$$
\varphi(x, t)=2 \pi B \int_{0}^{L} E^{2}(x, z, t) d z .
$$

Because the experimental setup is such that light polarized at an angle of $45^{\circ}$ to the direction of the applied field passes through the Lierr cell and then impinges upon an analyzer oriented perpendicular to the direction of polarization, the light transmitted by the analyzer obeys the relation

$$
\frac{I(x, t)}{I_{m}}=\sin ^{2}[\varphi(x, t) / 2] \text {. }
$$

In this equation we have again suppressed the $y$ dependence and $I(r, t) / I_{m}$ is the relative irradiance of the transnitted light at a position $r$ at any given time $t, I_{m}$ being the maximum transmitted irradiance. We have assumed that temporal and spatial variations in $I_{m}$, which are dependent solely on the light soures and the attenuation in the media through which the light beam propagates, are negligible; especially so in the present work, as we measured only the values of $r$ for which $I(x, t) / I_{m}=0$, i.e., the positions of the dark fringes.

It has been shown [27] that (3) can be rewritten

$$
\left(\frac{I(t)}{I_{m}}\right)_{x}=\sin ^{2}\left[\frac{\pi}{2}\left(\frac{\bar{E}(t)}{\bar{E}_{m}}\right)_{x}^{2}\right]
$$

where the overbar (e.g., in $\bar{A}$ ) denotes the following:

$$
\bar{A}=\left[\frac{1}{L} \int_{0}^{L} A^{2} d z\right]^{12}
$$

and $\left[I(t) / I_{m}\right]_{x}$ denotes $I(x, t) / I_{m}$ at a sperific value of $x$.

In (4), $\vec{E}_{m}$ is the smallest effective field strength that produces a maximum $I_{m}$ in the amount of transmitted light. Mothods have been developed to correct the ol served values of $\left(I(t) / I_{m}\right)_{s}$ for variations in the $x$ direction due to the fringing fields at thr electrodr ends [27]. However, these corrections were nit applied to the presint data because it has ben! show !revinusly that they modify values of $\left(\bar{E}(t), \bar{E}_{n}\right)_{x}$ nutarured with paraliel- 
plate electrodes greater than $10 \mathrm{~cm}$ in length and spaced lese than $1 \mathrm{~cm}$ apart by lese than 1 perent.

In this study information was obtained roneerning $[E(t)]_{x}$. and thus the space-charge density, at certain tims during the eycle of an applied steady-state alternating high-voltage operation. These data were obtained by illuminating the coll with a light pulse which was short compared to the observed temporal variation of the ficld. (Details were given in Section II.) To make explieit this situation (4) can be written

$$
\left(\frac{I}{I_{m}}\right)_{x, l}=\sin ^{2}\left[\frac{\pi}{2}\left(\frac{\bar{E}}{\overline{E_{m}}}\right)_{x, \ell}^{2}\right]
$$

where $t$ denotes the instant at which the observation is made.

Elcetric-field and space-charge distribution information were obtained from photographs of the trausmited fringe pattern at time $t$ (see, for example, Figs. 3 and 4 ). The relative positions $(x / d)$ of the centers of the dark bands along a centrally located path (of total length d) between and perpendicular to the inner rlectrode surfaces were measured and recorded. The ecenter of rach dark band or fringe was assumed to indicate a relative intrinsity of $\left(I / I_{m}\right)_{x_{1}}=0$, and thus, from (5), a point where the relative electric-ficld intensity $\left(\bar{E}_{/} / \bar{E}_{m}\right)_{x, t}$ was cyual to the square root of an even intrger. In kecping with the convention established earlier [10], [11], numerical values $n$ were assigned to rach dark fringe by counting $("=$ $0,2,4,6, \cdots)$ successively from the outermost dark region where $n=0$ inward to the desired fringe located on the scanning path (from $x / d=0$ to 1 ) between the electrodes (sen Figs. 3 and 4 ). The experimental values of $(x / d)$ and $\left(\bar{E} / \bar{E}_{m}\right)_{x, l}$ obtained from each photograph were fitted to a first-degree polynominal

$$
\left(\frac{\bar{E}}{\bar{E}_{m}}\right)_{\ell}=a+b(x / d)
$$

or to a second-degree polynominal

$$
\left(\frac{\bar{E}}{\bar{E}_{m}}\right)_{\ell}=A+B(x / d)+C(x / d)^{2}
$$

where $a, b, A, B$, and $C$ wele coefficients determined by a least squares best fit method [28]. The appropriate polynominal was judged to be sufficiently accurate whenever

$$
\left(\frac{\bar{E}}{\bar{E}_{m}}\right)_{\text {fitted }}=\left(\frac{\bar{E}}{\bar{E}_{m}}\right)_{\exp } \pm 0.05\left(\frac{\bar{E}}{\bar{E}_{m}}\right)_{\exp }
$$

In order to obtain the space-charge density $\rho$ from the electric-field distribution, the differential form of Gauss' law was used, i.e.,

$$
\frac{\partial E}{\partial x}=\frac{\rho}{\epsilon}
$$

where $\epsilon$ is the dielectric constant of the liquid medium. for the purposes of this paper numerical values of $\rho$ wore

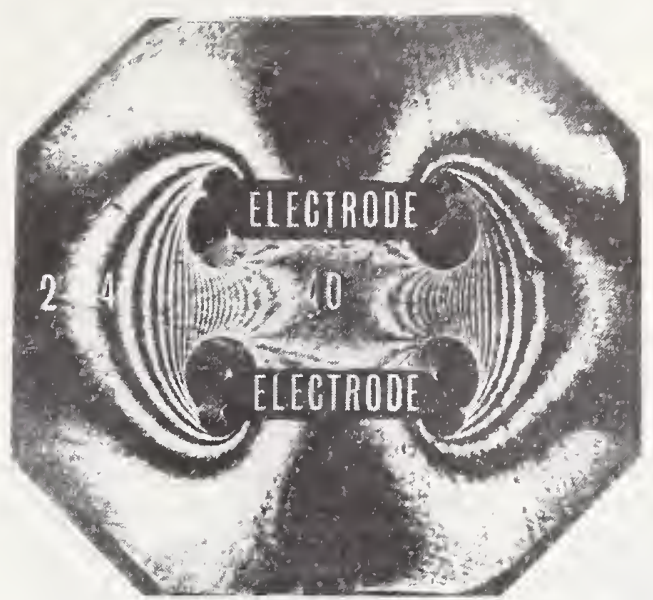

Fig. 3. Fringe pattern photographed (exposure time $0.3 \mu \mathrm{s}$ ) at the peak of a $6.5 .4-\mathrm{kV}$ total-duration $10-\mu \mathrm{s}$ pulsc. The fact that the field is uniform between the plates is demonstrated by the absence of interelectrode fringes. The side fringes are due to the fringing field along the length of the electrodes.

\section{STEADY-STATE VOLTAGES APPLIED}

dc

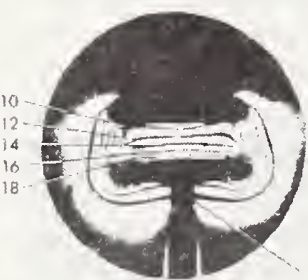

$18.00 \mathrm{kV}$ $60 \mathrm{~Hz} \mathrm{ac}$

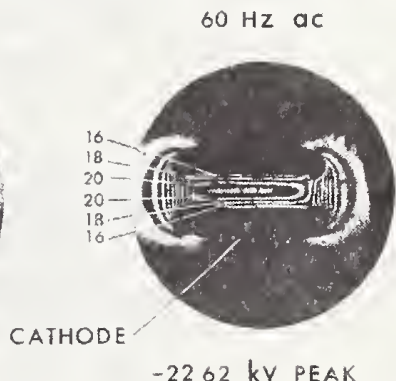

$-2262 \mathrm{kV}$ PEAK
Fig. 4. Typical observations of the fringe patterns resulting from the application of direct and $60-\mathrm{Hz}$ alt ernating voltages in cell $\boldsymbol{A}$. The interelectrode fringes show that the interelectrode field is not uniform under these eonditions. The fringe numbering procedure is described in Section III.

not needed, and, neglecting the effects of fringing end fields, (9) was reduced to

$$
\frac{\partial\left(\bar{E} / \bar{E}_{m}\right)_{\ell}}{\partial(x / d)}=\frac{\rho d}{E_{m} \epsilon}
$$

Computations of the coefficients in (6) and (7) were used to plot the electric-field distribution, i.e., $\left(\bar{E} / \bar{E}_{m}\right)$, as a function of $(x / d)$ and to allow convenient examination of space-charge effects in terms of the reduced space-charge density $\rho_{r}$ :

$$
\rho_{r}=\frac{\partial\left(\bar{E} / \bar{E}_{m}\right)_{\ell}}{\partial(x / d)} .
$$

Whenever a linear electric-field distribution, of which the de pattern in Fig. 4 is typical, was observed, (6) was fitted to the data and the reduced space-charge density was given simply by

$$
\rho_{r}=b \text {. }
$$

Whenever a parabolic-field distribution was computed 
(see, for example, the ac pattern in Fig. 4), the reduced space-charge distribution was determined as follows:

$$
\rho_{r}=B+2 C(x / d) .
$$

\section{EXPERINENTAL RESULTS}

It was reported earlier [11], [27] that electric fields produced by applying short $(5-20-\mu$ s duration) pulses as high as $300 \mathrm{kV}$ show no evidence of space-charge distortion. A typical Kerr-effect fringe pattern demonstrating this conclusion is given in Fig. 3. This photograph, which is a $0.3-\mu \mathrm{s}$ exposure taken at the peak of a $10-\mu \mathrm{s}$-long $65.4-\mathrm{kV}$ nearly rectangular pulse, shows the irradiance transmitted through a parallel-plate cell similar to those used in the present work. With this geometry, the field between the electrodes should be uniform. The pulsed field's compliance with this condition is verified experimentally by the uniformity in the irradiance (the absence of fringes) transmitted between the electrodes.

In contrast, Fig. 4 shows typical records taken during stcady-state de and $60-\mathrm{Hz}$ ac expcriments with the cell having parallel-plate glass-blasted nickel electrodes. The presence of space charge and its distortion of the interelectrode field is evident from the fringes recorded between the electrodes. Further, plotting (see Fig. 5) of the distorted field distributions from the fringe numbers and positions, as described in Section III, shows a profound difference between the $\mathrm{dc}$ and $60-\mathrm{Hz}$ field and charge distributions. Observations and discussions of these and other anomalies in steady-state dc and ac field distributions are discussed separately in the following sections. Discussions of the reproducibility of the electrical and electrooptical measurements are included, and several alternative explanations are presented and discussed. Because the data presented typify results from over 600 individual photographs, the majority of the data are
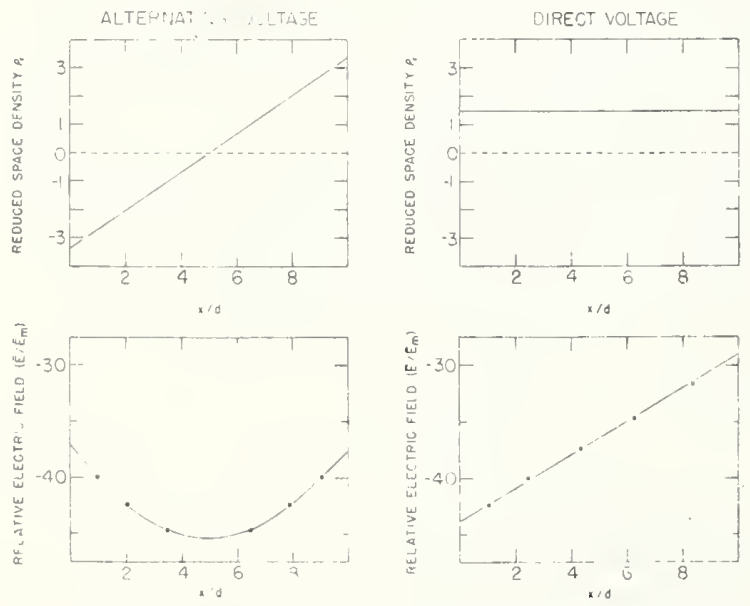

Fig. 5. The relative electric-field strength and the associated space-charge density as a function of relative position between the plates $(x / d)$. These data were obtained from the two photographs in Fig. 4. Although the average fiel? strengths are approximately the same in the two cases, the electric-field distribution, and consequently the space-charge densities, are radically different. presented in graphical form. A number of photographs of raw data are included to indicate to readers unfamiliar with this technique the types of observations that can be made.

\section{A. Measurements of Current Under Direct Voltage}

When the test cell is first filled with the purified nitrobenzene the current passed by the cell upon application of steady-state high voltage (alternating or direct) is very high, being as much as a thousand times greater than the steady-state current. For several minutes the conduction and electric-field properties of the cell are not stable and measurements, either electrical or optical, made during this period are nonrcproducible. After high voltage has becn applied for about half an hour, the current through the cell approaches a steady-state value, and further electrical and clectrooptical measurements are reproducible. However, when there is a significant time interval between voltage applications (e.g., overnight), or when the type of voltage excitation is changed (c.g., from direct to alternating or even if the polarity of direct voltage is changed), the current initially increases above the steady-state value but within a few minutes returns to the same steady-state value. During this period the electrooptic fringe pattern also changes slowly indicating changes in electric-field and space-charge distribution. Thus, whenever changes in voltage excitation are madc, reproducible measurcments reoccur only after several minutes of high-voltage conditioning. The eells in this study were used over a three-month period with the reproducibility of all measurements occurring after the brief conditioning periods. Other sealed cells have been in use for over three years with similar results. (Because nitrobenzene is hygroscopic, unsealed cells do not maintain this reproducibility.)

Other authors [29], [30] have noted both the decrease in eurrent with time during application of a constant high voltage and the dramatic increase in current with the decay back to a steady-state when the polarity is reversed. In their work, however, the clectrodes were coated with an electrodialytic varnish. In that case, the following explanation for current behavior was postulated [30]:

... the oncoming residual ions are trapped within the polymer matrix while electrical neutrality is preserved thanks to the stationary counterions; charge displacement in the reverse direction cannot occur unless the matrix has sufficient electronic conductivity. Of course, if voltage is reversed, the mobile ions are injected into the liquid and the arrangement works as a very efficient inject,s.

Howcver, as previously noted, the same time- and polarity-dependent behavior of the current was observed in our colls in which the electrodes were not varnished. A difierent, equally qualitative explanation for this behavior has been postulated [31]. This hypothesis, which secms a plausible and porhaps a more accurate explanation 
for our observations, contends that electrical conduction is primarily the result of the motion of micrometer-size particles carrying charges between the electrodes. If this is the case, two processes involving trapping of particles on the electrodes can account for the current bchavior.

1) Conducting micrometer- and subnicrometer-sized particles become trapped on insulating areas of the metallic electrodes because the insulating areas prevent them from readily giving up their charge to the metal electrode. This explanation accounts for both the decrease of eurrent with time (the trapping sites slowly fill, thereby reducing the density of charge carriers and thus the current) and for the increase of current with polarity reversal [31] (coulombic repulsion on reversal may be expected to restore the density of charge carriers temporarly to its original high value).

2) Fluid motion can bring small insulating particles in contact with one of the electrodes [15]. The particles eventually accept enough charge from the electrode to be repelled to the other electrode [32], where the charging and repulsive action are repeated. Under a constant applied voltage this process continues until the charge distribution in the liquid bulk eventually reaches a condition of steady-state current leakage and charge-induced distortion in the interelectrode ficld. Again, polarity reversal, whether under de or periodic ac conditions, interferes with these slower processes, causing increased repulsion and/or attraction of the particles from (or to) the electrode to which they are attached, and accordingly, an increase in current.

It should perhaps be noted that in addition to the work presented and referenced here concerning the effects of particles on the space-charge distribution in liquid insulators, there is a substantial body of literature concerned with the fact that the insulation strength of compressed gases is greatly reduced by free particles [33].

\section{B. Electric-Field Measurements and Charge Behavior with High Direct Voltage}

Typical field distribution data under direct voltage are shown in Fig. 6. This figure contains information obtained from fringe-pattern measurements by applying 0 - to \pm 30 $\mathrm{kV}$ direct voltage to one electrode of cell $A$ (see Table I). Several minutes of conditioning were allowed at each voltage level to insure steady-state operation. Schlieren observations during these experiments indicated that the dielectric fluid was in motion. The fringe patterns were, however, stable and reproducible after the conditioning period. This indicates that the equilibrium space-charge distribution in the liquid was stable in the presence of and in spite of steady-state fluid motion.

Fig. 7 shows explicitly the effects of high-voltage conditioning described earlier. The dashed lines show the electric-field distribution immediately after polarity reversal (the power-supply polarity was reversed so that the nongrounded electrode was changed from positive to negative). During $1 / 2 \mathrm{~h}$ of negative high-voltage operation, with sequence as shown in the figure, the field dis-

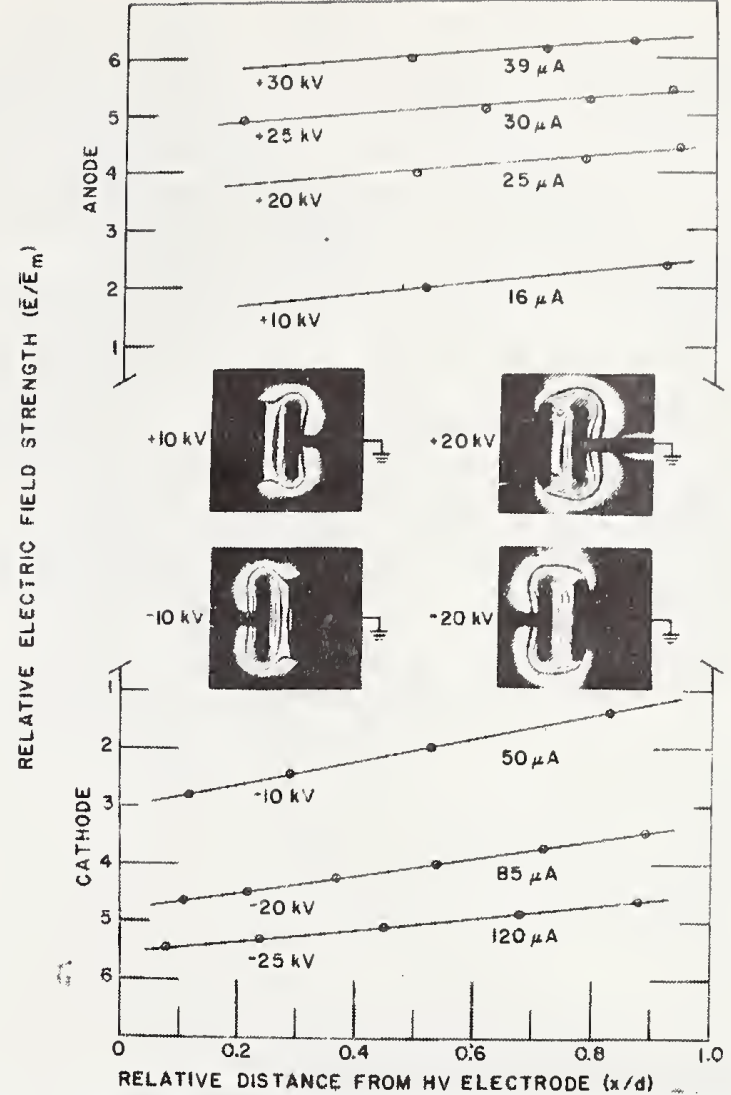

Fig. 6. Typical field distribution data under direct voltage in cell $A$. Photographs from which some of the data were taken are presented in the center of the figure. The presence of fringes behind the negative electrode is discussed in the text.

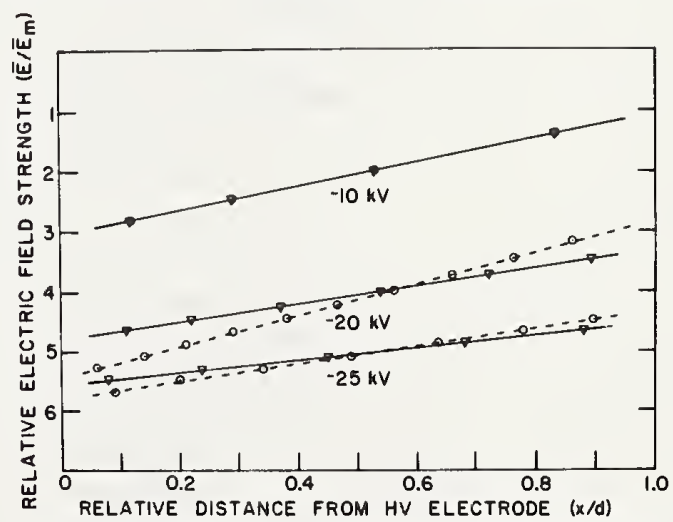

Fig. 7. This demonstrates the effects of high-voltage conditioning on the data presented in Fig. 6. The dashed lines represent the electric-field distribution immediately after the application of negative high voltage while the distribution obtained after high voltage was applied for about a half hour is shown by the solid line.

tribution shifted to those shown by the solid lines. These results are in agreement with those reported by previous workers [20], [34], insofar as all observations show that the field distribution shifts with time when ligh voltage is first applied to the plates. It is noted, however, that the shape of the field distributions reported by earlier workers differs from those shown in Figs. 6 and 7. This difference is probably attributable to differences in our electrodes; 
they used varnished brass electrodes, while the present results were obtained using a ccll equipped with bare nickel electrodes. Further evidence suggesting that the field shape is affected by the electrode material is presented in discussion of Figs. 11 and 14 which show the difference between ac field-distribution results when using stainless-steel and nickel electrodes, respectively.

Calculations of the interelectrode field distribution, i.e., of $\left(\bar{E}_{/} / \bar{E}_{m}\right)_{x, \ell}$ as a function of relative position $(x / d)$ between the electrodes, and of the reduced space-charge density or were performed as desclibed in Section III. In the de cases the field distributions were computed and plotted by fitting the data to a first-degree polynominal, (6). In this case $\rho_{r}$ was independent of the relative position $(x / d)$ between the electrodes and its value was detcrmined from (12).

Results calculated from the measurements of Figs. 4 and 5 with cell $A$ and from similar typical experiments with cell $B$ are listed in Table II. Inspection of the results shows several trends over the range studied: 1 ) the net charge in the liquid was always positive and uniformly distributed in the bulk;2) the space-charge density in the bulk decreased as the applied voltage (average field) increased; 3 ) the net charge in the liquid bulk was slightly greater when negative high voltages were applied; 4) the net charge in the liquid was reduced by cxtended highvoltage operation (conditioning); and 5) the net density of spacc charge was greatcr in the cell with nickel electrodes (cell $A$ ).

These trends lend evidence to the postulate that lcakage conduction is dominated by the motion of small particles between the plates. Previous work [29] has shown that if the particles were metallic with a work function smaller than the work function of the electrodes, the particles would reccive a greater positive charge at the positive electrode than negative charge at the negative clectrode. Because nickel has a very large work function it is likely that in our case such conducting particles would have a smaller work function and therefore that the net spacecharge density would indeed be positive.

Similarly, thesc trends are also compatible with the postulate that the current conduction is governed by the action of insulating particles, in this case perhaps of submicrometer-size alumina particles which were imperceptibly carried with the liquid in passing from the chromatographic column during the process described in Section II. If this be the case, the insulating particles may be cxpected to be attracted to and form a resistive layer or dielectric coating on the electrode surfacc. This layer would be expected to incrcase in thickness with voltage and time, thereby slowly reducing the net charge circulating in the bulk and thus the leakage current through the liquid. On removal of the voltage, the attached particles would detach from the electrode and drift sluwly back into the bulk. Upon reapplication of voltage they would repeat the same procedure, except that the initial current and rate of decay may be expected to be smaller duc to the fact that some particles will undoubtedly remain at-
TABLE II

Reduced Space-Charge Density in Bulk of Liquid During High Direct Voltage Operation

\begin{tabular}{c|c|c}
\hline \multicolumn{2}{|c}{} & \multicolumn{2}{|c}{ CELI A } \\
\hline \multirow{2}{*}{ Applied } & \multicolumn{2}{|c}{ Reduced Charge Density } \\
\cline { 2 - 3 } Voltage & Before Cond1tioning & After Conditioning \\
\hline \multirow{2}{*}{$(\mathrm{kV})$} & $P_{\mathrm{r}}$ & $P_{\mathrm{T}}$ \\
+10 & - & 0.87 \\
+20 & - & 0.88 \\
+25 & - & 0.77 \\
+30 & - & 0.62 \\
-10 & 2.35 & 2.35 \\
-20 & 2.64 & 1.54 \\
-25 & 1.43 & 0.90 \\
\hline
\end{tabular}

CELL B

\begin{tabular}{c|c|c}
\hline+15 & 0.64 & - \\
+30 & 0.56 & 0.47 \\
+35 & - & 0.39 \\
-30 & - & 0.21 \\
\hline
\end{tabular}

tached to the electrodes. On polarity reversal, similar behavior would be expected exccpt that the electrode of attraction would change with the polarity.

Schlicren observations of the liquid behavior on removal of the applied high voltage also tend to substantiate the particle postulate. Schlicren movies beginning immediatcly brfore and continuing after sudden removal of high direct voltages show development of localized changes in the index of refraction of the liquid near the electrodes, with gradual development (over a period of several minutes) of differing refractive indices in the upper and lower regions of the test cell in a manner suggestive of gradual settling of the particles under gravity to the lower regions of the ccll.

Onc additional discussion of the de data is in order. The typical photographs in Fig. 6 show significant light transmission behind the negative electrodc. Some light transmission is, of course, expreted duc to fringing fields behind the electrodes, but these fringing fields would be symmetric about both electrodes and hardly cvident at lower voltages. Yet Fig. 6 indicates that a field of significant intensity exists behind the negative slectrode. The fringes behind the cathode in the $+20-\mathrm{kV}$ pattern, for example, indicate that $(4)^{1 / 2}<\left(\bar{E} / \bar{E}_{m}\right)<(6)^{1 / 2}$ in the region adjacent to the back of the cathode surface. In this ccll, for which $\bar{E}_{m}=9.8 \mathrm{kV} / \mathrm{cm}$, this indicates that $\bar{E} \approx 22 \mathrm{kV} / \mathrm{cm}$ immediately adjacent to the back surface, that $\bar{E}=0$ at a point located about $0.5 \mathrm{~cm}$ from the back surface of the negative elcetrode. This enhancement of the field behind the negative electrode probably results from the presence of positively charged particles in the liquid bulk. Under the influence of the imposed alcetrostatic forces the particles would move to and collect about the 
cathode, including its back side, and cause the observed field enhancement. The irradiance around the cathodesupport rod in Fig. 6 supports the postulate that charged particles also collect around this portion of the electrode. The fact that $\bar{E}$ gocs to zero at a point on the electrode support could indicate that the accumulation of charged particles in this region of the liquid is limited by the shielding of charged particles already attached to the electrode or by fluid motions which cause the particles to be concentrated in certain regions of the liquid.

Such observations, indicating the existence of space charge in the bulk of the liquid behind an electrode, have not, to the authors' knowledge, been previously reported. Accordingly, this unforseen behavior and its contribution to electrical stress in liquids are areas for further theoretical and experimental work. In the meantime, several trends are noted from the present work as characteristic of this effect. 1) The field enhancement behind the electrode always appears behind the cathode, whether or not it is grounded, thereby ruling out the possibility that it may result simply from stray capacitance between the highvoltage electrode and ground. 2) The field enhancement is most pronounced under steady-state direct-voltage operation; it is barely noticeable under steady-statc ac conditions (see Figs. 4 and 8). Under ac conditions the rapid variation of the electric field will not allow charged particles to collect behind an electrode; the particle does not have enough time to travel to the back surface of an electrode before the electrode polarity is reversed. Furthermore, Schlieren observations of the liquid during ac steadystate operation show that the fluid motion is much more turbulent than under de conditions. This greater turbulence would also tend to disperse any particles tending to collect near a given electrode. 3) The magnitude of the enhancement is affected both by the lcvel of applied voltage and by the duration of exposure to high-voltage operation: in a continuous experiment the enhancement was observed to increase with voltage level, as is evident from the +10 and $+20-\mathrm{kV}$ fringe patterns in Fig. 6 (one fringe behind the electrode at $10 \mathrm{kV}$ and nearly three at $20 \mathrm{kV}$ ) which were taken after days of intermittent exposure to voltage of positive polarity. In widely spaced experiments and those performed without extensive conditioning, the behavior of this enhancement is as yet less predictable. For example, the -20 - and $-10-\mathrm{kV}$ patterns were taken in that order after about 50 min of exposure to voltage of negative polarity; the paiterns show greater enhancement at $-10 \mathrm{kV}$ (after longer conditioning) than at $-20 \mathrm{kV}$. Another fringe pattern, that recording the data for the $-10-\mathrm{kV}$ curve in Fig. 6 (immediately after reversal of the voltage polarity), shous greatcr enhancement (3-4 fringes) behind the electrode before conditioning. The cells were oriented with the plates horizontal and it was consistently observed that there was greater enhancement when the negative electrode was the lower rather than the upper elcctrode. It is therefore conceivable that the gravitational force might not be negligiule in this case. It is evident, however, that further specific experimental observations are needed for a detailed and accurate explanation of the causes of field distortion and current leakage in the liquid bulk.

\section{Measurements with Alternating High Voltages}

Fringe-pattern data concerning the clectric-field distribution, and hence the spacc-charge density and distribution, werc taken under a variety of alternating highvoltage conditions. 1) Observations were made at the positive peak of sinusoidal voltagcs of various levels (to $30 \mathrm{kV} \mathrm{rms}$ ) and frequencies (between 40 and $200 \mathrm{~Hz}$ ). 2) Observations were made at $(1 / 16) T$ intervals over the course of an entire cycle of such operations. 3) As in the de studies, these observations werc conducted using both cell $A$ and $B$ so as to bring out bchavioral differences which might be attributable to the electrode materials. Typical results from thesc studies are presented and discussed in the following paragraphs.

Fig. 8 shows the fringe patterns photographed at the positive maximum of a $22-\mathrm{kV}$-rms sinusoidal voltage at various frequencies between $40-10 ; \mathrm{Hz}$ using cell $B$. The significant obscrvation from these photographs is that the number of interelectrode fringes is frequency dependent, with a maximum at approximately $80 \mathrm{~Hz}$. Typical data from frequency studies at $25 \mathrm{kV}$ rms, obtained from twenty different fringe-pattern photographs, are compiled in Table III. In this table the relative position $x / d$ of each transmission minimum, $\left(\bar{E} / \bar{E}_{m}\right)_{x, t^{2}}=n$, is tabulated with the frequency of the applied voltage as a parameter. It is immediately obvious that the number of interelcctrode fringes is frequency dependent, with a broad maximum in the vicinity of $80-105 \mathrm{~Hz}$. From these data, the spacechargc density as a function of the frequency of the applied voltage can be calculated [(11) and (12)]. Graphs showing the reduced space-cliarge density $\rho_{r}$ as a function of the frequency of the applied voltage at two different voltage levels arc shown in Figs. 9 and 10. These data, like those in Fig. $S$ and in Table III, are the results of observations taken at the positive maximum of the applied voltage. Two conclusions can be seen from the plotted $\rho_{r}$ versus frequency curves: as the magnitude of the alternating voltage is increased, the frequency at which the maximum space charge occurs shifts toward higher frequencies and the magnitude of the maximum space charge increases.

During the course of this study, data werc taken not only at the positive maximum of the applied voltage but also at selected points during the cycle of the applied voltage. Field distributions plotted from typical observations at various times during a cycle of $15-\mathrm{kV}-\mathrm{rms} 60-\mathrm{Hz}$ operation using cell $B$ are shown in Fig. 11. We note that the electric-field distribution is linear with positive slope throughout the whole cycle. If we extrapolatc to zero, (1/2) $T$, or $T$, the field distribution is linear, being equally positive and negative about the center $(c / d=0.5)$. Fig. 12 shows some of the fringe patterns from which these plots were obtained. Note that at time $(1 / 2) T$, the applied voltage is instantancously zcro, yet light appears near the 

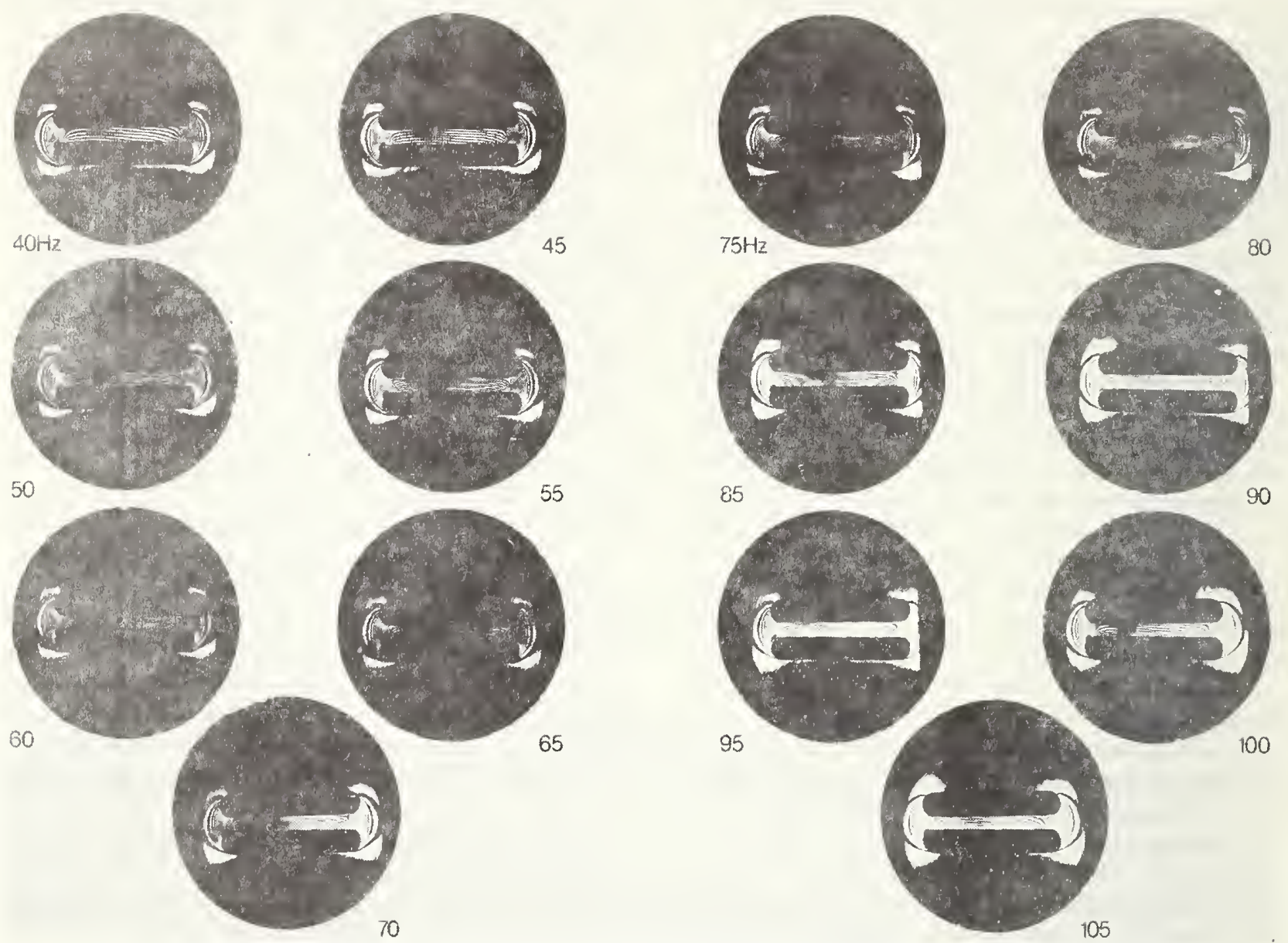

Fig. 8. Photographs showing the fringe patterns taken at the positive peak of a $22-k V-r m s$ sinusoidal voltage at various frequencies between $40-105$. It can be seen that the number of interelectrode fringes is frequency dependent with a maximum at approximately $80 \mathrm{~Hz}$.

TABLE III

Fringe Position $x / d$ as a Function of Frequency with $25 \mathrm{kV}$ RMS Applied to Cell $B$

\begin{tabular}{|c|c|c|c|c|c|c|c|c|c|c|c|c|c|c|c|c|c|c|c|c|}
\hline $\begin{array}{c}\text { Frequency } \\
\quad \mathrm{Hz}\end{array}$ & 40 & 45 & 50 & 55 & 60 & 65 & 70 & 75 & 80 & 85 & 90 & 95 & 100 & 105 & 110 & 115 & 120 & 125 & 130 & 135 \\
\hline \multicolumn{21}{|l|}{$\begin{array}{l}\text { Frlnge } \\
\text { No. n }\end{array}$} \\
\hline 46 & & & & & & & & & & .06 & .02 & .02 & & & & & & & & \\
\hline 48 & & & & & & .02 & .01 & .06 & .07 & .11 & .08 & .08 & .05 & .02 & & & & & & \\
\hline 50 & & & & & .02 & .10 & .09 & .12 & .13 & .15 & .13 & $.13^{\prime}$ & .09 & .08 & & & & & & \\
\hline 52 & & & & & .10 & .18 & .16 & .17 & .18 & .20 & .18 & .17 & .13 & 12 & & & & & & \\
\hline 54 & & .08 & .13 & .11 & .20 & .25 & .22 & .23 & .23 & .26 & .22 & .22 & .18 & .17 & .02 & & & & & \\
\hline 56 & .35 & .31 & .29 & .25 & .30 & .32 & .29 & .29 & .28 & .32 & .28 & .28 & .23 & .22 & .07 & .05 & & & & \\
\hline 58 & .59 & .47 & .43 & .39 & .40 & .40 & .38 & .35 & .34 & .38 & .34 & .34 & .30 & .29 & .13 & .11 & .08 & .04 & .03 & \\
\hline 60 & .77 & .62 & .58 & .54 & .50 & .49 & .45 & .43 & .41 & .45 & .41 & .40 & .37 & .35 & .21 & .18 & .15 & .09 & .08 & .05 \\
\hline 62 & .91 & .75 & .72 & .71 & .62 & .58 & .55 & .51 & .49 & .52 & .47 & .47 & .44 & .42 & .29 & .27 & .23 & .16 & .16 & .11 \\
\hline 64 & & .88 & .85 & .88 & .75 & .68 & .65 & .59 & .56 & .59 & .54 & .54 & .51 & .50 & 37 & .36 & .32 & .25 & .25 & .19 \\
\hline 66 & & .97 & 96 & .98 & .88 & .79 & .75 & .67 & .64 & .65 & .61 & .60 & .58 & .57 & .47 & .46 & .41 & .34 & .38 & .30 \\
\hline 68 & & & & & .98 & .88 & .85 & .75 & .71 & .72 & .68 & .68 & .64 & .63 & .56 & .55 & .52 & .47 & 5 & .45 \\
\hline 70 & & & & & & .97 & .91 & .84 & .79 & .79 & .74 & .74 & .71 & .68 & .63 & .64 & .60 & .57 & $.6=$ & .59 \\
\hline 72 & & & & & & & & .91 & .86 & .85 & .81 & .81 & .78 & .75 & .70 & .72 & .68 & .67 & .72 & .72 \\
\hline 74 & & & & & & & & .98 & .93 & .91 & .87 & .87 & .85 & .81 & .77 & .79 & .75 & .75 & . 80$)$ & .80 \\
\hline 76 & & & & & & & & & .98 & .97 & .93 & .93 & .91 & .87 & .83 & .86 & .81 & .83 & $.8 i$ & .88 \\
\hline 78 & & & & & & & & & & & .98 & .98 & .96 & .92 & .90 & .92 & .97 & .89 & .93 & .94 \\
\hline 80 & & & & & & & & & & & & & & .97 & .97 & .98 & .93 & .95 & & \\
\hline & & & & & & & & & $\begin{array}{l}x / \mathrm{d} \\
5 \mathrm{kv}\end{array}$ & & & & & & & & & & & \\
\hline
\end{tabular}




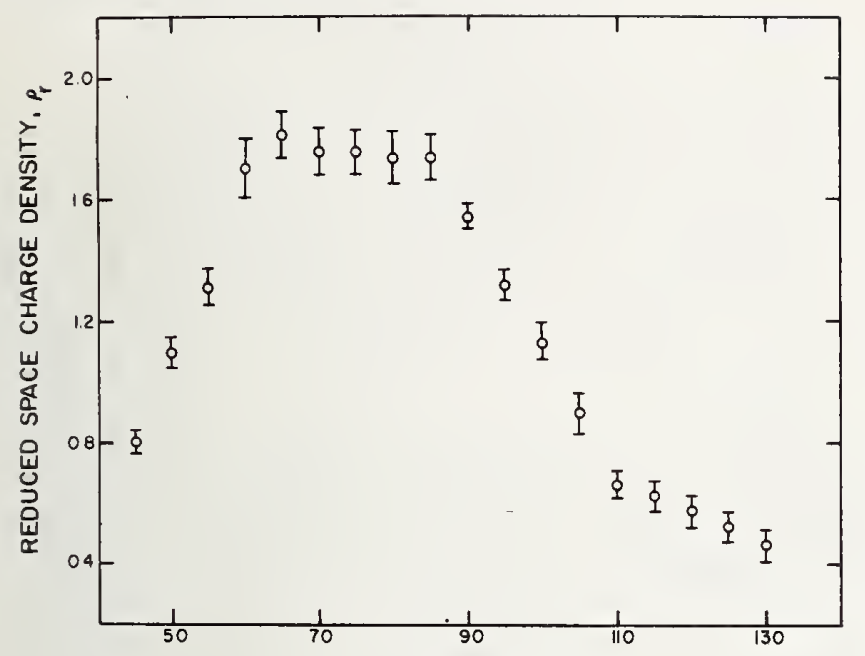

FREQUENCY $(\mathrm{Hz})$

Fig. 9. The reduced space-charge density $\rho_{r}$ in cell $B$ as a function of the frequency of an applied $15-\mathrm{kV}$-rms voltage. Each data point was determined from the electric-field distribution observed at the positive peak of the applied sinusoidal voltage. The error bars indicate the standard deviation of the coefficient $\rho_{\mathrm{r}}$ as determined from a linear least squares fit of the electric field between the electrodes. Note that the reduced space-charge density has a maximum at a frequency of approximately $60 \mathrm{~Hz}$.

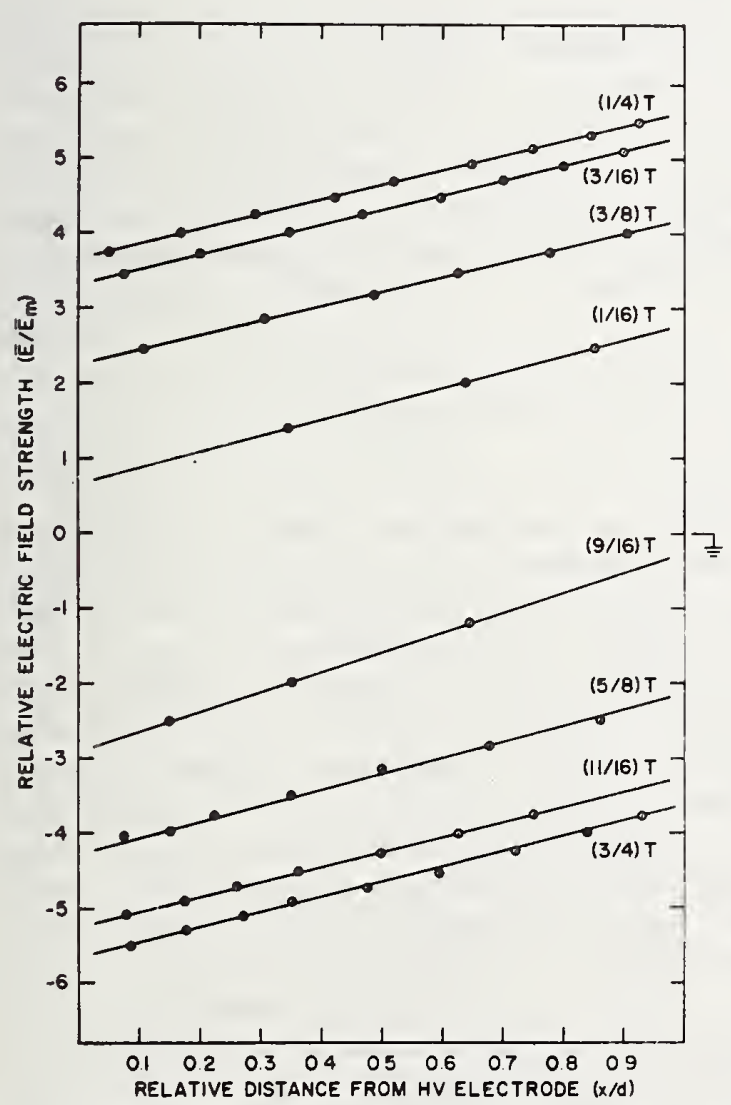

Fig. 11. The electric field distribution in cell $B$ at varicus times during the cycle of $60-\mathrm{Hz} 15-\mathrm{kV}-\mathrm{rms}$ applied voltage. The period of the applied waveform is denoted $T$, so, for example, tine data designated as $1 / 4 T$ were taken at the positive maximum of the applied voltage.

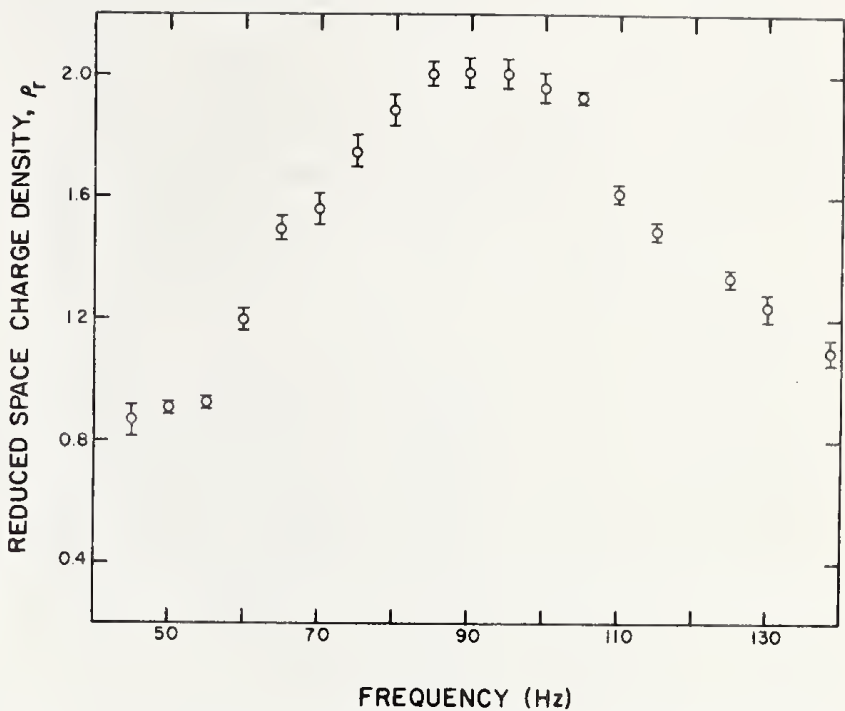

Fig. 10. The reduced space-charge density as a function of the frequency of an applied 25-kV-rms voltage. The meaning of each data point is the same as in Fig. 9. In comparison with Fig. 9 the maximum reduced space-charge density has shifted to a higher frequency of approximately $90 \mathrm{~Hz}$.

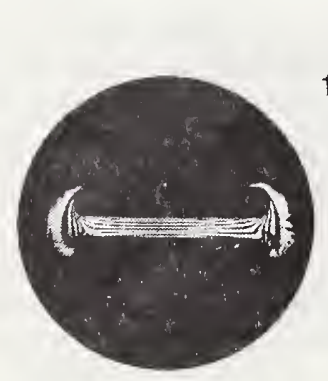

\section{$60 \mathrm{~Hz}$}

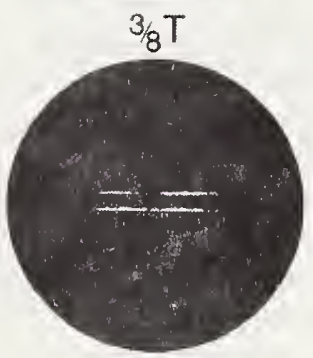

$15 \mathrm{kV} r \mathrm{rs}$
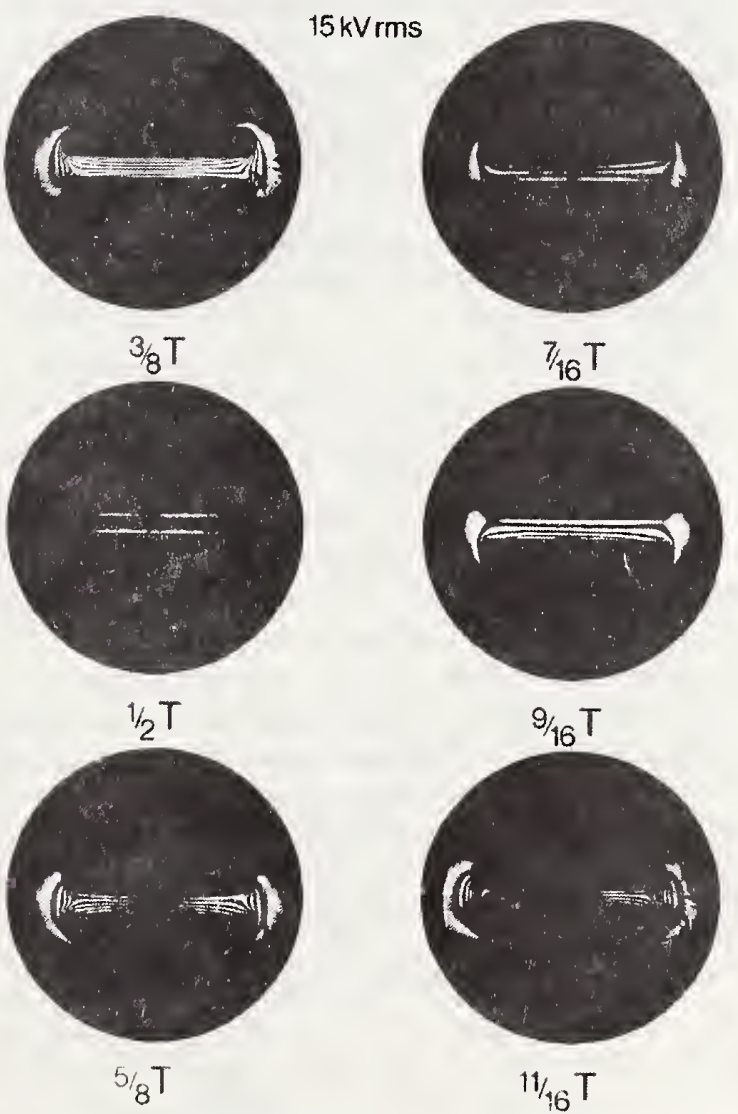

Fig. 12. Photographs from which some of the data in Fig. 11 were taken. Note that there is some light transmitted at $1 / 2 T$, i.e., wher the voltage is instantaneously zero. As explained in the text, this indicates that the bulk space-charge density is constant throinghout the cycle. 

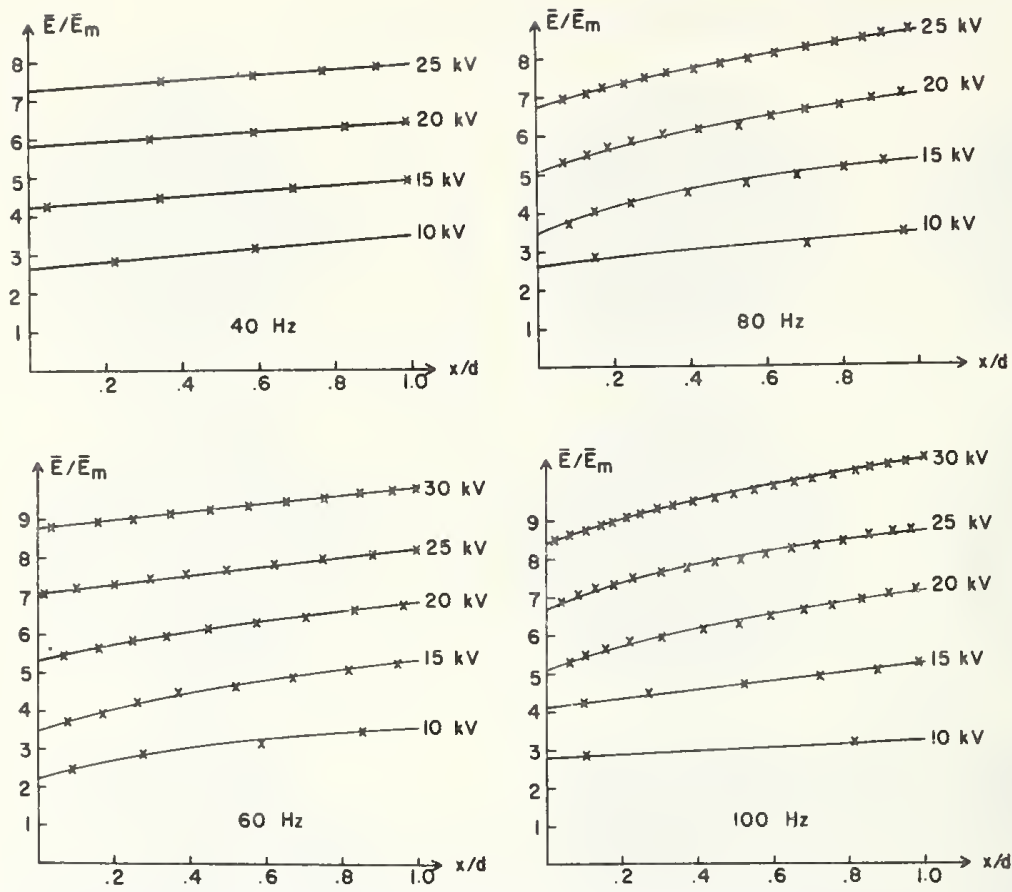

Fig. 13. The electric-field distribution at selected frequencies and voltage levels in cell $B$. All of the data in this figure were taken at the positive maximum of the applied voltage.

electrodes. When the voltage is instantaneously zero, the total surface charges on each electrode are negative and equal in magnitude, while the total volume bulk charge is double in magnitude and positive, keeping the system neutral. (The surface charge per unit area on the electrodes can be computed by the discontinuity of the normal component of $\epsilon \bar{E}$.) At other times in the cycle, the volumecharge density remains constant (independent of voltage polarity), while the surface charge on the electrodes varies sinusoidally with time.

It is also interesting to note from Fig. 12 that again some light, although over a much smaller area than was found with dc voltages, is also transmitted behind the cathode during ac operation. Further measurements over the complete cycle show this anomalous field enhancement follows the sinusoidal cycle, alternating between electrodes, as the field enhancement always appears behind that electrode which is instantaneously negative.

Measurements of the electric field as a function of position at the positive maximum of the applied voltage at various voltage levels and selected frequencies are plotted in Fig. 13. From this type of observation, the following results, showing relationship between the frequency $f_{\max }$ at which the net space-charge density was maximum and the applied-voltage level, were obtained:

\begin{tabular}{cc}
$\begin{array}{c}\text { Measurements of } f_{\max } \\
\text { Voltage } \\
(\mathrm{kV} \text { rms })\end{array}$ & $\begin{array}{c}\text { at Various Voltage Levels Using Cell } B \\
f_{\max } \\
(\mathrm{Hz})\end{array}$ \\
\hline 10 & $45-65$ \\
12 & $55-65$ \\
15 & $60-85$ \\
20 & $80-95$ \\
22 & $80-95$ \\
25 & $90-105$ \\
\hline
\end{tabular}

Similar measurements with cell $A$ showed many of the same features. The de field was observed to be a linear function of position between the electrodes (see Fig. 5), again indicating a uniformly distributed net positive charge in the liquid bulk. In addition, observations at the peak voltages during ac operation at various frequencies indicated that the distortion in the ac field, and thus the density of charge in the liquid, was again frequency dependent. Measurements with $20 \mathrm{kV}$ rms applied showed, for example, that the field distortion and charge density were maximum at approximately $100 \mathrm{~Hz}$, thereby demonstrating good agreement with the $B$-cell measurements which showed $f_{\max }=80-95 \mathrm{~Hz}$ at $20 \mathrm{kV} \mathrm{rms}$ (see previous table).

There were, however, also significant differences between the $A$ and $B$ observations. The $A$-cell fringe-pattern measurements consistently showed that the $A$-cell ac electric field is not a linear function of position, and that the field distribution varies periodically with time during each cycle of ac operation, being periodically uniform and nonuniform as may be seen from the field measurement data plotted in Fig. 14. The curves show that maximum distortion occurs near the positive and negative peaks of the alternating voltage waveform. Moreover, observations at these times showed that the interelectrode ficld in this cell has an inverted "U-shaped" distribution (see the ac results in Figs. 5 and 14). Whereas a linear ficld distribution was found typical in cell $B$, this inverted U-shaped distribution, which implies the presence of positive space charge near the anode and negative charge near the cathode (a situation noted by Croitoru [19] as being indicative of charge injection at the electrodes), was found typical of cell $A$ at the voltage peaks during ac operation. 


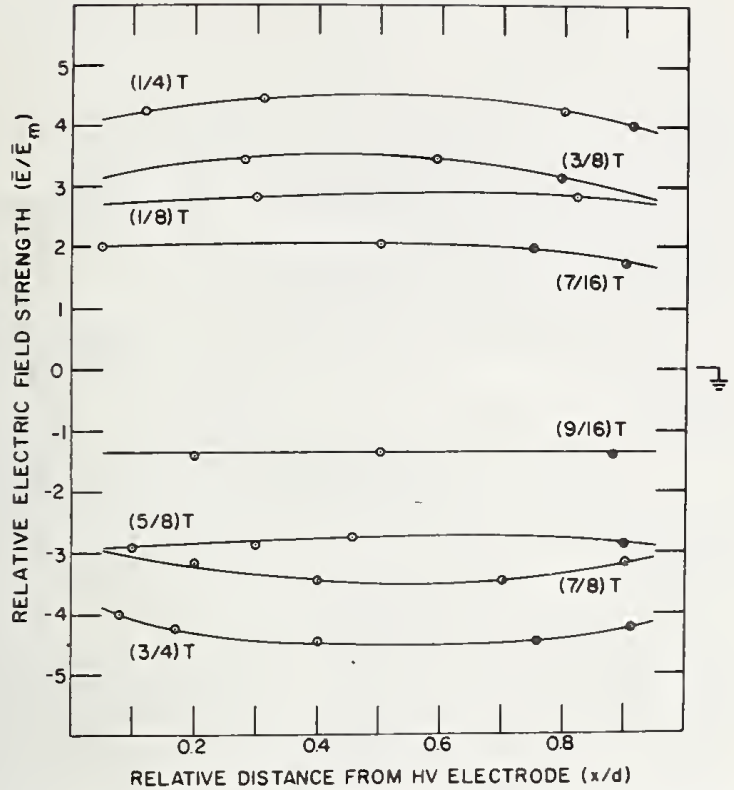

Fig. 14. The electric-field distribution in cell $A$ as a function of time with a $60-\mathrm{H}_{2} 15-\mathrm{kV}-\mathrm{rms}$ applied voltage. Note that in this cell the field distribution is no longer linear, but varies periodically during a cycle.

Finally, since the field-distributions characteristic of each cell were found to be reproducible for substantial periods of time, in spite of repeated refillings of the cells with nitrobenzene, we have felt it reasonable to attribute the differences between their ac field distributions to the differences in their electrode materials and/or surface preparations. Verification of this conclusion and distinction of the relative contributions of the material from those of the surface conditions will, however, require further study.

\section{SUMMARY AND CONCLUSIONS}

Our purpose has been to document, from examination of results from extensive Kerr-effect fringe-pattern observations in nitrobenzene, several space-charge-induced trends in the behavior of an insulating liquid under the stress of high-voltage operation. We have demonstrated experimentally that electric-field distributions in the bulk of the liquid are predictable only during operation under short (microsecond) pulse conditions. Results from observations during de and low-frequency ac operation have shown that the interelectrode electric-field and spacecharge distributions are dependent upon the level and frequency of the applied voltage, the electrode material and their surface condition, and the immediate previous history of the system.

In a cell with electropolished stainless-steei electrodes, the interelectrode-field distribution was approximately linear and the net space-charge density was positive during operation under high dc and low-frequency voltages. Further, the net charge measured during operation at a given ac voltage (i.e., at a constant $\mathrm{rms}$ level) was found to be independent of the instantaneous voltage. The net charge in the liquid bulk between the electrodes remained constant throughout the entire course of the ac cycle, even when the instantaneous voltage was zero, thereby suggesting that the field and charge distributions in this cell are governed primarily by a steady-state arrangement of charged particles uniformly distributed and suspended in the bulk by the steady streaming motion of the liquid between and around the electrodes.

Observations with a cell having glass-blasted nickel electrodes showed different results. The interelectrodefield distribution was linear under direct voltage, but parabolic under alternating voltages. The obscrved ac fields were weaker near the clectrodes and stronger in the region midway between them, thereby implying the formation of positive space charge near the anode and negative charge near the cathode. As might be expected in a charge injection process, the electric-field distribution and charge density in the bulk also varied as a function of time (and thus voltage) during each cycle of ac operation. The difference between the field and charge behavior in the two cells is attributed to their differences in clectrode materials and surface conditions.

Except for these features, essentially the same behavior was observed in both cells. Their de fields were both linear functions of position between the electrodes, and both showed space-charge enhancement of the field behind the negative electrode. This latter effect is maximum for direct voltages and decreases with excitation voltage frequency, whereas electrohydrodynamic motion of the liquid (always observed during steady-state high-voltage operation), distortion of the interelectrode field, and charge density in the liquid are much more pronounced during low-frequency ac operation.

With regard to the distortions in the ac fields, the distributions observed were found to be frequency dependent; as the frequency of the exciting voltage was increased the charge measured in the liquid bulk between the electrodes increased. The plot of space-charge density versus frequency exhibited a maximum, with this maximum shifting toward higher frequencies as the voltage level is increased. As the frequency of excitation was further inereased, the field distribution became uniform and the space-charge density in the liquid approached zero, as would be expected when the time between polarity reversals was too short for charge collection in the liquid near and around the electrodes.

Finally, though these observations still offer no conclusive results for reliable prediction of steady-state field and charge behavior (and thus of the onset of breakdown) in an insulating liquid, they do demonstrate several important, as yet undocumented trends to be expected in the bulk of the liquid when under the stress of highvoltage operation. It is hoped that the experimenta evidence presented will stimulate the further research and theoretical investigation needed for a more thorough understanding of the mechanisms of breakdown in liquidinsulated high-voltage equipment. 


\section{REFERENCES}

[1] S. Y. Ettinger and A. C. Venezia, "High voltage pulse measuring system based on Kerr effect," Rev. Sci. Instr., vol. 34, pp. 221-224, 1963.

[2] D. C. Wunsch and A. Erteza, "Kerr cell measuring system for high voltage pulses," Rev. Sci. Instr., vol. 35 , pp. 816-820, 1964.

[3] E. C. Cassidy, H. N. Cones, D. C. Wunsch, and S. R. Booker, "Calibration of a Kerr call system for high-voltage pulse measurements," IEEE Trans. Instrum. Meas. (1968 Conf. Precision Electromagnetic Measurements), vol. IM-17, pp. 313320, Dec. 1968.

[4] F. C. Cassidy, H. N. Cones, and S. R. Booker, "Development and evaluation of electrooptical high-voltage pulse measurement techniques," IEEE Trans. Instrum. Meas. (1970 Conf. Precision Electromagnetic Measurements), vol. IM-19, pp. 395402, Nov. 1970.

[5] A. W. Bright, B. Makin, and A. J. Pearmain, "Field distribution in nitrobenzene using the Kerr effect," Brit. J. Appl. Phys. (J. Phys. D), vol. 2, pp. 447-451, 1969.

[6] P. Atten and J. P. Gosse, "Regime transitoire de conduction lors d'une injection unipolairc dans les liquids isolants." in Phenomenes de Conduction dans Liquidcs Isolants. Paris, France: Editions du Centre National de la Researche Scientifique, 1970 , pp. $325-343$.

[7] E. A. Cherney and J. D. Cross, "Space charge effects in chlorobiphenyls," IEEE Trans. Elec. Insul., vol. EI-8, pp. 10-16, Mar. 1973.

[8] J. D. Cross and R. Tobazeon, "Electric field distortions produced by solid dielectric spacers separating uniform field electrodes in nitrobenzene," IEEE Trans. Elec. Insul., vol. EI-8, pp. 25-29, Mar. 1973.

[9] R. E. Hebner and E. C. Cassidy, "Measurement of $60 \mathrm{~Hz}$ voltages using the Kerr effect," Rev. Sci. Instr., vol. 43, pp. 1839-1841, 1972.

[10] E. C. Cassidy and H. N. Cones, "A Kerr electro-optical technique for observation and analysis of high intensity electric fields,"J. Res. Nat. Bur. Stand., Sec. C, vol. 73, pp. 5-13, 1969.

[11] E. C. Cassidy, "Pulsed laser Kerr system polarimeter for electro-optical fringe pattern measurement of transient electrical parameters," Rcv. Sci. Instr., vol. 43, pp. 886-892, 1972.

[12] C. E. Hill and H. House, "The problems in using the Kerr electro-optic effect to measure the field distributions in nonpolar liquids," in Phenomenes dc Conduction dans Liquides Isolants. Paris, France: Editions du Centre National de la Researche Scientifique, 1970 , pp. 465-481.

[13] M. Zahn and J. R. Melcher, "Space charge dynamics of liquids," Phys. Fluids, vol. 15, pp. 1197-1205, 1972.

[14] M. Zahn, "Dynamics of stratified liquids in the presence of space charge," Phys. Fluids, vol. 15, pp. 1408-1417, 1972.

[15] W. R. L. Thomas, "The nature of particulate charge carriers in $n$-hexane and their role in electrohydrodynamic phenomena," in 1972 Annu. Rep. Conf. Electrical Insulation and Dielectric Phenomena (Nat. Acad. Sci., Washington, D. C.), 1972, pp. $52-59$

[16] A. W. Bright and B. Makin, "Modern electrostatic generators," Contemp. Phys., vol. 10, pp. 331-353, 1969.
[17] A. M. Zarem, F. R. Marshall, and F. L. Poole, "An electrooptical shutter for photographic purposes," AIEE Proc., vol. 68, pp. 84-91, 1949

[18] F. J. McClung and R. W. Hellwarth, "Giant optical pulsations from ruby," J. A ppl. Phys., vol. 33, pp. 828-829, 1962.

[19] Z. Croitoru, "Space charges in dielectrics," in Progress in Dielectrics, vol. 6, J. B. Birks and J. Hart, Ed. New York: Academic, 1965, pp. 103-146.

[20] W. F. Pickard, "Electrical force effects in dielectric liquids," in Progress in Dielectrics, vol. 6, J. B. Birks and J. Hart, Ed. New York: Academic, 1965, pp. 1-39.

[21] H. T. Jessop and F. C. Harris, Photoelasticity, Principles and Mfethods. New York: Dover, pp. 68-70.

[22] J. H. Park, "Special shielded resistor for high-voltage DC measurements," J. Res. Nat. Bur. Stand., vol. 66C, pp. 19-24, 1962.

[23] J. F. Housley, "Reconditioning of insulating oils by activated alumina," AIEE Trans., vol. 58, pp. 172-178, Apr. 1939.

[24] J. D. Ramshaw, D. W. Schaefer, J. S. Waugh, and J. M. Deutch, "Dielectric polarization and alignment and the structure of polar fluids," J. Chem. Phys., vol. 54, pp. 1239-1251, 1971 .

[25] G. Nienhuis and J. M. Deutch, "Structure of dielectric fluids II. The free energy and the Kerr effect in polar fluids," $J$. Chem. Phys., vol. 56, pp. 235-247, 1972.

[26] P. Mazur and B. J. Postma, "On the molecular theory of the Kerr effect," Physica (Utrecht), vol. 25, pp. 251-267, 1959.

[27] E. C. Cassidy, W. E. Anderson, and S. R. Booker, "Recent refinements and developments in Kerr system electrical measurement techniques," IEEE Trans. Instrum. Meas. (1972 Conf. Precision Electromagnetic Measurements), vol IM-21, pp. 504-510, Nov. 1972.

[28] Details of the fitting procedure can be found in J. Hilsenrath et al., Omnitab, A Computer Program for Statistical and Numerical Analysis, National Bureau of Standards Handbook 101, U. S. Government Printing Office, Washington, D. C., pp. $124-140$.

[29] R. Tobazeon, "Comportement du nitrobenzene pur sous champs intenses continus et alternatifs," in Phenomenes de Conduction dans Liquides Isolants. Paris, France: Editions du Centre National de la Researche Scientifique, 1970, pp. 407-422.

[30] N. J. Felici, "DC conduction in liquid dielectrics," Direct Current, vol.2, pp. 90-99, 1971

[31] Z Krasucki, "High-field conduction in liquid dielectries," in Phenomenes dc Conduction dans Liquides Isolants. Paris, France: Editions du Centre National de la Researche Scientifique, 1970, pp. 311-323.

[32] A. Y. H. Cho, "Contact charging of micron-sized particles in intense electric fields," J. A ppl. Phys., vol. 35, pp. 2561-2564, 1964.

[33] For a recent discussion of these effects see A. H. Cookson and O. Farish "Particle-initiated breakdown between coaxial electrodes in compressed $\mathrm{SF}_{6}, "$ IEEE Trans. Power A pp. Syst., vol. PAS-92, pp. 871-876, May/June 1973.

[34] G. Briere and J. Gosse, "Electrodialyse des solvants polaires," J. Chim. Phys. Physicochim. Biol., vol. 68, pp. 1341-1348, 1968. 
1. J. H. Park and H. N. Cones, "Sphere-Gap Volt-Time Curves--Reference Standards for Steep Front Measurements" Am. Inst. Elec. Engrs. Conference Paper, Reprint No. 57-215, 1957.

2. E. Kuffel and M. Abdullah, "High Voltage Engineering" Pergamon Press, New York, p. 273, 1970.

3. D. C. Wunsch and A. Erteza, "Kerr Cel1 Measuring System for High Voltage Pulses" Rev. Sci. Instru., vol. 37, pp. 816-820, 1964.

4. International Electrotechnical Commission, "High Voltage Test Techniques" IEC Publication 60, 1962.

5. E. C. Cassidy, W. E. Anderson, S. R. Booker, "Recent Refinements and Developments in Kerr System Electrical Measurement Techniques" IEEE Trans. Instru. and Meas., vol. IM-21, pp. 504-510, 1972.

6. E. C. Cassidy, R. E. Hebner, Jr., M. Zahn, and R. J. Sojka, "KerrEffect Studies of an Insulating Liquid under Varied High Voltage Conditions" IEEE Trans. Elec. Insul., vol. EI-9, pp. 43-56, 1974.

7. E. C. Cassidy, R. E. Hebner, R. J. Sojka and M. Zahn, "Development and Analysis of Techniques for Calibration of Kerr Cell PulseVoltage Measuring Systems VII" NBS Report NBS IR 73-403, November 1973.

8. E. C. Cassidy and H. N. Cones, Development and Analysis of Techniques for Calibration of Kerr Cell Pulse-Voltage Measuring Systems IV" NBS Report 10 296, August 1970.

9. C. G. Le Fevre and R.J.W. Le Fevre, "The Kerr Effect. Its Measurement and Applications in Chemistry" Rev. Pure Appl. Chem., vol. 5, pp. 261-318, 1955 .

10. A. D. Buckingham and R. E. Raab, "A Molecular Theory of the Electrooptical Kerr Effect in Liquids" J. Chem Soc., pp. 2341-51, 1957.

11. A. von Hippel, "Tables of Dielectric Materials Volume IV" Technical Report No. 57, Laboratory for Insulation Research, Massachusetts Institute of Technology, January 1953.

12. G. L. Clark, "Dielectric Properties of Nitrobenzene in the Region of Anomalous Dispersion" J. Chem. Phys., vol. 25, pp. 125-129, 1956.

13. N. J. Felici, "DC Conduction in Liquid Dielectrics" Direct Current, vol. 2, pp. 90-99, 1971.

14. R. E. Hebner, Jr., R. J. Sojka, and E. C. Cassidy, "Kerr Coefficients of Nitrobenzene and Water" NBS IR 74-554, August 1974. 
15. Details of the fitting procedure can be found in J. Hilsenrath, et.al., "OMNITAB, A Computer Program for Statistical and Numerical Analysis" NBS Handbook 101, U.S. Government Printing Office, Washington, D.C., pp. 124-140.

16. E.C. Cassidy, "Development and Analysis of Techniques for Calibration of Kerr Cell Pulse Voltage Measurement Systems V" NBS Report 1-493, October 1971.

17. P. D. Thacher, private communication.

18. J. B. Hasted, "Liquid Water: Dielectric Properties" Water A Comprehensive Treatise, F. Franks, ed., Plenum Press, New York, vol. 1, p. 262, 1972 .

19. E. A. Cherney and J. D. Cross, "Space Charge Effects in ChIorobiphenyls" IEEE Trans. Elec. Insul., vol. EI-8, pp. 25-29, 1973.

20. Z. Croitoru, "Space Charges in Dielectrics" in Progress in Dielectrics, vol. 6, J. B. Birks and J. Hart, ed., Academic Press, Inc., New York, pp. 103-146, 1965.

21. H. H. Woodson and J. R. Melcher, Electromechanical Dynamics, vol. II, J. Wiley and Sons, Inc., New York, p. 383, 1968.

22. W.R.L. Thomas, "The Nature of Particulate Charge Carriers in n-Hexane and Their Role in Electrohydrodynamic Phenomena" 1972 Annual Report Conference on Electrical Insulation and Dielectric Phenomena, National Academy of Sciences, Washington, D.C., pp. 52-59, 1972 .

23. Y. Hawaguchi, H. Murata and M. Ikeda, "Breakdown of Transformer Oil" IEEE Trans. Power Appar. Sys. PAS-91, pp. 9-23, 1972. 
